Sharif University of Technology
Scientia Iranica
SCIENTIA $\quad \begin{gathered}\text { Transactions D: Computer Science Es Engineering and Electrical Engineering } \\ \text { I RAN I C A }\end{gathered}$

Research Note

\title{
Optimal scheduling of hydrothermal system considering variable nature of water transportation delay
}

\author{
D. $\operatorname{Das}^{\mathrm{a}, *}$ A. Bhattacharya ${ }^{\mathrm{b}}$, and R.N. Ray ${ }^{\mathrm{a}}$ \\ a. Department of Electrical Engineering, National Institute of Technology, Agartala, Tripura, Pin-799046, India. \\ b. Department of Electrical Engineering, National Institute of Technology, Durgapur, West Bengal, Pin-713209, India. \\ Received 8 February 2019; received in revised form 8 July 2019; accepted 7 December 2020
}

\author{
KEYWORDS \\ Grasshopper \\ optimization; \\ Hydrothermal \\ scheduling; \\ Water-to-power \\ conversion; \\ Water time delay; \\ Valve point loading.
}

\begin{abstract}
This paper presents an algorithm called Grasshopper optimization for solving short-term hydrothermal scheduling problem. The objective of this problem is to reduce the generation cost by optimizing the output of power generation of different thermal and hydro plants for a certain time interval. A non-linear relationship between hydropower generation, net head, and rate of water discharge is considered here. A complex piecewise output limit and head-sensitive conversion of water-to-power is applied here. To investigate the performance of this new technique, three test systems have been considered. The results obtained by this Grasshopper optimization algorithm are compared with those of other wellknown soft computing techniques. The efficacy of this proposed technique was verified after comparison with other similar soft techniques.

(C) 2022 Sharif University of Technology. All rights reserved.
\end{abstract}

\section{Introduction}

A great challenge faced by the power sectors in recent years remains high costs of fuel generation and the objective is to reduce the consumption of fossil fuel. In modern power systems, a large number of generating plants of various types are scheduled to deliver power to load centers. The objective of Hydrothermal Scheduling (HTS) is to generate power optimally so as to minimize the production cost of thermal units while satisfying various constraints including limits of hydro discharge, thermal and hydropower generation limit, availability of water, and power balance. Various inequality and equality constraints and valve point effect must be included in a practical HTS problem. Therefore, the resulting HTS becomes a problem of non-convex optimization. It is still difficult

\footnotetext{
*. Corresponding author.

E-mail address: diptanuonline@yahoo.co.in (D. Das)
}

to solve this problem by traditional methods such as Dynamic Programming (DP) [1], gradient search [2], Non-Linear Programming (NLP) [3], Lagrange multiplier method [4], Mixed Integer Linear Programming (MILP) [5], or any other suitable method. DP is quite popular as compared to other classical methods. However, the main drawback of DP is that its computational time increases rapidly following an increase in system size. Linear programming can be applied if the characteristic of fuel cost is quadratic. The main disadvantage of MILP is that the simulation time and memory size increase exponentially when more integer values are incorporated.

Therefore, in recent years, various soft computing methods have been proposed for solving various HTS problems. In 1994, Wong and Wong proposed Simulated Annealing (SA) [6] method to solve shortterm HTS problems. Various constraints such as power balance constraints, volume limits of reservoir, and water discharge constraints were considered. In order to check the limits, a relaxation technique was incorporated in the algorithm. The results obtained by this 
method showed that this algorithm had the capability to attain global optimal solution. A coarse-grained parallel SA technique was developed by Wong and Wong [7] for solving HTS problems. The performance of this method was investigated using a test example and it was observed that the results obtained by this technique were better than those of the sequential SA method. However, the main drawback of SA method is that its convergence speed is low and the tuning of parameters is a challenging task. In 1996, Chen and Chang introduced Genetic algorithm (GA) [8] for scheduling of the hydraulically coupled plant. The hydrothermal iteration and successive approximation of the reservoir were not required here. Results obtained by this technique revealed that this approach produced a better solution than the other conventional methods. In1998, GA was incorporated by Orero and Irring [9] in HTS problems. It was found that GA gave a better quality solution to the HTS problem considering net head variation and transport delay of water. The biggest limitation of GA is that it cannot give guarantee of optimality and with increase in system size, the quality of solution deteriorates. Therefore, various modifications have been made to improve the efficiency of GA. Gil et al. [10] proposed GA that simultaneously handled the unit commitment, economic dispatch, and coordination of short-term hydrothermal problems. In order to improve the behavior of GA, sets of expert operators were introduced. It was found that this Improved GA (IGA) had the ability to obtain a near-optimal solution in a reasonable time. Kumar and Naresh [11] developed a real coded GA for the solution of the HTS problem. The performance of this method in a cascaded hydrothermal plant was observed considering non-linear function of hydro generation. The binary coded GA was also implemented to check the performance. Both features are the same, except mutation and crossover. Evolutionary Programming (EP) technique was implemented by Hota et al. [12] for HTS problems. The simulation results achieved by EP were compared with SA and gradient search approaches. It was seen that this method provided better quality solution results than the results of SA and gradient search method. In 2013, Sinha et al. [13] proposed a fast EP method for solving HTS problems. Improved Cauchy mutation and Gaussian method were developed to increase the convergence rate and to obtain a good quality solution. It was examined that the solution quality, convergence rate, and computational efficiency of EP method outperform those of other EP methods. Mandal et al. developed Particle Swarm Optimization (PSO) [14] for solving HTS problems. A non-linear relationship among power generation, discharge rate, and net head was considered [14]. Three thermal plants along with four hydro plants were considered. Simulation results revealed that this technique gave a good quality solution than the other well-known optimization methods such as SA and EP. However, the main drawback of PSO is that the solution obtained by this technique tends to get stuck in a local optimal point. In order to overcome the drawbacks of PSO, various modifications and hybridizations were conducted. In 2012, Wang et al. [15] applied improved self-adaptive PSO in order to solve shot-term HTS issues. The evolution direction of particle was dynamically redirected to avoid premature convergence. The effectiveness was validated on a system containing one thermal unit and four hydro units. In 2018, the two-swarm based PSO search method was developed by Cavazzini et al. [16] for solving HTS problems. The adaptive search diversification PSO was modified using a secondary swarm that dealt with infeasible solution, whereas the primary one dealt with a feasible solution [16]. Six test cases were considered here to validate the performance of this new strategy. Differential Evolution (DE) was incorporated by Mandal and Chakraborty [17] for solving short-term hydrothermal problems. The water time delay between the reservoirs was considered. The results obtained by this method were compared with those of other optimization methods [17]. It was observed that DE method was capable of yielding promising results. The major disadvantage of $\mathrm{DE}$ method is its slow convergence rate when a large test system is considered. To promote the exploitation and exploration ability of DE, Sivansubramani and Swarup [18] developed an improved DE method for solving HTS problems. In this paper, DE was hybridized with Sequential Quadratic Programming (SQP) where DE enhanced the exploration capability. In 2014, Basu introduced an improved DE [19] for solving shortterm HTS problems. In order to improve search efficiency, Gaussian random variable was used instead of scaling factor. Basu [20] proposed Hopfield neural networks to solve fixed head hydrothermal problems. Results obtained by this method show that this technique enjoyed the capability to obtain a near-optimal solution. Similarly, in recent years, various metaheuristic and heuristic methods and their hybridized forms like Teaching Learning Based Optimization (TLBO) [21], quasi-oppositional TLBO (OTLBO) [22], Cuckoo Search Algorithm (CSA) [23], Multi-Objective Artificial Bee Colony optimization (MOABC) [24], Symbiotic Organisms Search (SOS) [25], Chemical Reaction Optimization (CRO) [26], Grey Wolf Optimizer (GWO) [27], Real Coded Chemical Reaction Optimization (RCCRO) [28], Krill herd algorithm [29], clonal section algorithm [30], flower pollination algorithm [31], sine cosine algorithm [32], Ant Lion Optimizer (ALO) [33], Whale Optimization Algorithm (WOA) [34], Modified CSA [35], Quasi-Reflected Symbiotic Organisms Search (QRSOS) [36], quasi-reflected 
ions motion optimization [37], improved predator influenced civilized swarm optimization [16,38], Real Coded Genetic Algorithm with Artificial Fish Swarm Algorithm (RCGA-AFSA) [39], ORCCRO [40], Modified Chaotic Differential Evolution (MCDE) [41], modified dynamic neighbourhood learning based PSO [42], hybrid CRO [43], Non-dominated Sorting Gravitational Search Algorithm integrated with Disruption operator (NSGSA-D) [44], Hybridized gravitational search algorithm [45], Parallel Multi-Objective Differential Evolution (PMODE) [46], Hybrid Particle Swarm Optimization approach with Small Population size (HPSO-SP) [47], Quasi-Oppositional Group Search Optimization (QOGSO) [48], Parallel multi-objective GA [49], Improved harmony search algorithm [50], adaptive selective CSA [51], couple-based PSO [52], improved cloud adaptive quantum-inspired binary social spider optimization algorithm [53], and hybrid ABCBAT algorithm [54] have been applied to short-term hydrothermal problems to ensure a faster convergence speed and achieve near-optimal solutions.

In 2017, Grasshopper Optimization Algorithm (GOA) [55] was proposed by Saremi et al. for solving structural problems. This optimization method functions based on the grasshopper swarm activities [55]. The observations made by this method were compared to those of various well-known methods. It was found that the proposed method provided a better quality solution than other optimization techniques. The advantages of GOA method are as follows:

- In nature, grasshoppers conduct extensive exploration by avoiding contact with each other. Thus, the algorithm can avoid local optima [55];

- High exploitation and convergence results in this algorithm due to the attraction between grasshopper and the comfort zone were adopted by them [55];

- High attraction between grasshoppers and also the adaptive nature of the co-efficient of comfort zone help make a balance between the exploration and exploitation properties [55];

- GOA exhibits a high exploitation ability while solving problems involving unimodal test functions. For multi-modal test functions, it will be very effective between exploration and exploitation while finding a solution to problems having composite functions. For all these qualities, GOA remarkably outperforms many recent algorithms while solving a wide variety of optimization problems [55].

In this paper, authors have applied GOA to solve the short-term HTS problem [36]. In order to check the feasibility of this algorithm, two test systems have been considered. It is observed that the result obtained by this GOA method is superior than those of the other well-known algorithms. The main contributions of this paper are as follows:

- In most of the HTS problems, a fixed value of water transportation delay is generally considered which is not a practical one. The transportation delay varies with a hydro reservoir discharge rate. It is a nonlinear water discharge function. In this work, the non-linearity of water transportation delay with the discharge rate of water has been considered. This is a real aspect of operation in HTS;

- Hydropower generation mainly depends on the volume of water. In the conventional method of HTS, the volume of water is considered that may not match with the realistic condition. In this paper, a different approach has been adopted to consider the volume of water represented by three different sets of equations categorized into three segments [56];

- Water transportation delay has been incorporated in this proposed method of HTS.

\section{Problem formulation}

\subsection{Objective function}

The main objective of HTS is to reduce the cost of the generation of thermal power units while satisfying various inequality and equality constraints [25]. The price of hydro power units is negligible [36]. The fitness function of HTS problem is given below [36]:

$$
\min C_{T}=\sum_{I=1}^{N T} \sum_{t=1}^{T N} F_{I}\left(T H_{p}(I, t)\right),
$$

where $N T$ is the number of thermal units. $T N$ represents the number of intervals [36]. $T H_{p}$ indicates power generation of thermal unit of the $I$ th plant at time interval $t$ [25]. The cost function of thermal plants without considering valve point effect is represented by the following equation [36]:

$$
\begin{aligned}
F_{I}\left(T H_{p}(I, t)\right)= & \alpha_{I s}+\beta_{I s} \times T H_{p}(I, t) \\
& +\gamma_{I s} \times T H_{p}^{2}(I, t) .
\end{aligned}
$$

The cost function of thermal plants considering valve point effect can be represented by the following equation $[36,57]$ :

$$
\begin{aligned}
F\left(T H_{p}(I, t)\right)=\alpha_{I s}+\beta_{I s} \times T H_{p}(I, t) \\
+\gamma_{I s} \times T H_{p}^{2}(I, t)+\left|\begin{array}{l}
\delta_{I s} \times \sin \left(\varepsilon_{I s} .\right. \\
\left(T H_{p}^{\min }(I)\right. \\
\left.\left.-T H_{p}(I, t)\right)\right)
\end{array}\right| \\
I=1,2, \cdots, N T, \quad t=1,2, \ldots, T N,
\end{aligned}
$$

where $\alpha_{I s}, \beta_{I s}, \gamma_{I s}, \delta_{I s}$, and $\varepsilon_{I s}$ represent fuel cost 
coefficients of the $I$ th thermal unit and $\left(T H_{p}^{\min }(I)\right.$ indicates the minimum limit of the thermal power generation.

\subsection{Equality and inequality constraints}

Various constraints associated with HTS problems are given below.

\subsubsection{Continuity constraints of hydraulic network}

The reservoir flow balance or the equation [58] of continuity depends on the transportation delay between two reservoirs. The equation of flow balance relates to the previous interval with net discharge [58], and inflow and storage volume of hydro reservoir of the present interval. The volume of water at time interval $t$ must satisfy the following equation [36]:

$$
\begin{gathered}
V O_{h}(i, t)=V O_{h}(i, t-1)+I N_{h}(i, t) \\
-D I_{h}(i, t)+\sum_{m \in Y_{u}(i)} D I_{h}\left(m, t-\tau_{m}\right) \\
i=1,2, \cdots, N H \quad t=1,2, \cdots, T N,
\end{gathered}
$$

where $V O_{h}(i, t), I N_{h}(i, t)$, and $D I_{h}(i, t)$ denote the final hydro reservoir storage volume, inflow rate, and discharge of hydro reservoir of the $i$ th hydro plant at time interval $t$, respectively [25,36]. NH represents the total number of hydro unit numbers [25]; $\tau_{m}$ is the delay of water transport [25]. $Y_{u}(i)$ denotes the upstream plants numbers which are above and connected to hydro unit $i[36]$.

\subsubsection{Limits of discharge and storage volume of hydro reservoir}

The amount of water discharge for any particular reservoir should not violate the lower and upper limits of water discharge because these reservoirs are used to supply water for farming and other purposes [36].

$$
V O_{h}^{\min }(i) \leq V O_{h}(i, t) \leq V O_{h}^{\max }(i) .
$$

The discharge rate of hydro plants must lie within their minimum and maximum discharge levels [36].

$$
\begin{aligned}
& D I_{h}^{\min }(i) \leq D I_{h}(i, t) \leq D I_{h}^{\max }(i) \\
& \quad i=1,2, \ldots, N H, \quad t=1,2, \ldots, T N,
\end{aligned}
$$

where $V O_{h}^{\min }(i), V O_{h}^{\max }(i)$ represent the lower and upper limits of the $i$ th hydro reservoir storage volume [36]. $D I_{h}^{\min }(i), D I_{h}^{\max }(i)$ indicate the lower and upper limits of water discharge of the $i$ th hydro reservoir [36].

\subsubsection{Initial and terminal reservoir storage limits}

This is generally set by the mid-term scheduling process. This equality constraint implies that the total quantity of available water is fully utilized. Initial and final reservoir volumes are given by [36]:

$$
\begin{gathered}
V O_{h}(i, 0)=V O_{h}^{\text {begin }}(i), \\
V O_{h}(i, T N)=V O_{h}^{e n d}(i), \\
i=1,2, \ldots, N H
\end{gathered}
$$

where $V O_{h}^{\text {begin }}$ and $V O_{h}^{e n d}$ denote the initial and terminal storage volumes of the $i$ th hydro reservoir.

\subsubsection{Prohibited discharge zones}

The reservoir of hydro plant may have a certain discharge zone where the operation of hydro units is restricted $[27,36]$ because vibrations in the components at certain power output are observed. It is found that when the vibration frequency equals the natural frequency, resonance occurs [36]. This can harm the apparatus. The rate of discharge of hydro reservoir including prohibited discharge zone can be represented as follows [36]:

$$
\begin{aligned}
& D I_{h}(i) \in\left\{\begin{array}{l}
D I_{h}^{\min }(i) \leq D I_{h}(i, t) \leq D I_{h}^{L,(1)}(i) \\
D I_{h}^{U(u-1)}(i) \leq D I_{h}(i, t) \leq D I_{h}^{L(u)}(i) \\
D I_{h}^{U(P Z)}(i) \leq D I_{h}(i, t) \leq D I_{h}^{\max }(i)
\end{array}\right. \\
& u=2,3, \cdots, P Z
\end{aligned}
$$

where $D I_{h}^{L}(i, t)$ and $D I_{h}^{U}(i, t)$ are the minimum and maximum limits of the $u$ th prohibited zones of hydro plant $i[36]$. $P Z$ indicates the number of the prohibited discharge zones.

\subsubsection{Limits of generations}

The total number of thermal and hydro power generations should not exceed the lower and upper limits of generation, which are represented by the following equations [36]:

$$
\begin{aligned}
& T H_{p}^{\min }(I) \leq T H_{p}(I, t) \leq T H_{p}^{\max }(I) \\
& \quad I=1,2, \ldots, N T, \quad t=1,2, \ldots, T N,
\end{aligned}
$$

where $T H_{p}^{\min }(I), T H_{p}^{\max }(I)$ are the minimum and maximum generation limits of the $I$ th thermal unit.

$$
\begin{aligned}
& H R_{p}^{\min }(i) \leq H R_{p}(i, t) \leq H R_{p}^{\max }(i) \\
& \quad i=1,2, \ldots, N H, \quad t=1,2, \ldots, T N
\end{aligned}
$$

where $H R_{p}(i, t)$ is the output of the $i$ th hydro plant at time interval $t . H R_{p}^{\min }(i), H R_{p}^{\max }(i)$ indicate the lower and upper power output limits of the $i$ th hydro unit [36]. The hydropower generation is a function 
of storage volume and discharge of water, which is represented as follows [36]:

$$
\begin{aligned}
& H R_{p}(i, t)= W_{1 i} \times V O_{h}^{2}(i, t) \\
&+W_{2 i} \times D I_{h}^{2}(i, t)+W_{3 i} \times V O_{h}(i, t) \\
& \times D I_{h}(i, t)+W_{4 i} \times V O_{h}(i, t) \\
&+W_{5 i} \times D I_{h}(i, t)+W_{6 i} \\
& i=1,2, \cdots, N H, \quad t=1,2, \cdots, T N
\end{aligned}
$$

where $W_{1 i}, W_{2 i}, W_{3 i}, W_{4 i}, W_{5 i}$, and $W_{6 i}$ are the coefficients of generation.

\subsubsection{Power balance constraints}

Total power generation by thermal and hydro units at any time interval $t$ must satisfy the load demand and loss of the system at particular interval of time [36]. This equation can be represented by the following equation $[36,58]$ :

$$
\begin{aligned}
& \sum_{I=1}^{N T} T H_{p}(I, t)+\sum_{i=1}^{N H} H R_{p}(i, t) \\
& \quad=P O_{\text {Demand }}(t)+P O_{\text {Loss }}(t),
\end{aligned}
$$

where $P O_{\text {Demand }}(t)$ and $P O_{\text {Loss }}(t)$ represent the load demand and transmission losses at time interval $t$ [58].

\subsubsection{Equations of water-to-power conversion}

Hydropower generation can be calculated based on the volume segment of water due to dependency of hydro power generation mainly on the water volume. The hydropower generation characteristic may be represented by a linear water-to-power conversion curve [56] by assuming the storage reservoir volume as constant. This curve shows the relation of the discharge of input water $D I_{h}$ to the generation of power output $T H_{p}$, as depicted in Figure 1 [56]. Linear fitting method is used to formulate the linear function when the volume of water is at the interval $n$ [56]. The water-to-power conversion function can be represented as follows [56]:

$$
\begin{aligned}
& H R_{p}(i, t)=e_{h, n}(i, t) \times D I_{h}(i, t)+f_{h, n}(i, t) \\
& \mathrm{V}_{h, n-1} \leq V O_{h} \leq V_{h, n}, \quad H R_{h, t} \geq 0
\end{aligned}
$$

where $H R_{p}(i, t)$ represents hydro power output of unit $i$ at time interval $t$ [56]. $\quad e_{h, n}(i, t)$ is the water-topower conversion slope of hydropower plant $i$ in volume segment $n ; f_{h, n}(i, t)$ represents the water-to-power conversion intercept of hydropower plant $i$ in volume segment $n$. $V O_{h}(i, t)$ indicates the volume of storage of unit $i$ in the $n$ segment of water-to-power conversion constraints [56]. In Figure 1, $D I_{h, t, n}^{\prime}$ indicates one

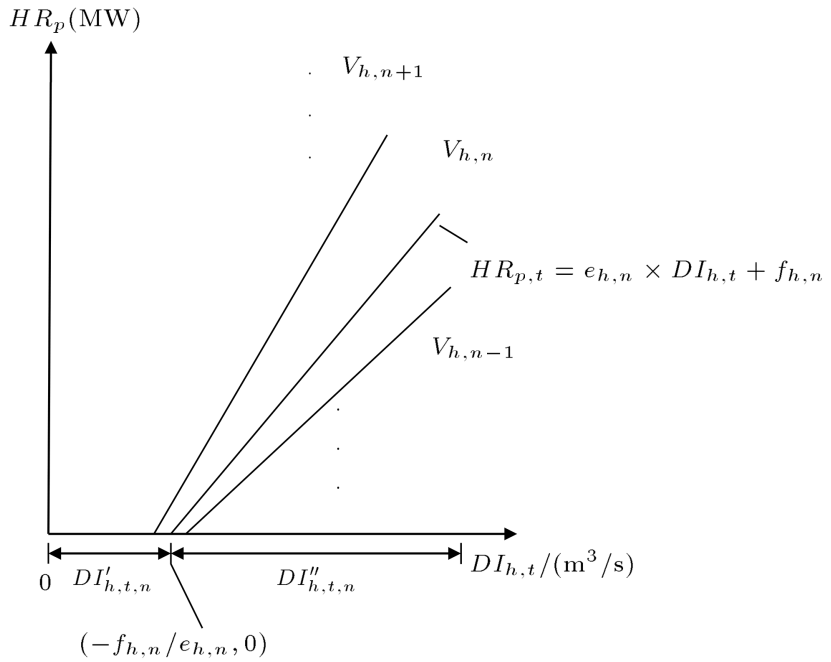

Figure 1. Hydropower generation curve.

section of $D I_{h, t, n}\left[D I_{h, t, n}\right.$ is the discharge of water of hydropower plant in the $n$th volume segment at time $t$ which is divided into two sections (in $\mathrm{m}^{3} / s$ )] and the value of range is $\left[0,-f_{h, n} / e_{h, n}\right] . \quad D I_{h, t, n}^{\prime \prime}$ is another section of $D I_{h, t, n}$ (in $\mathrm{m}^{3} / s$ ) and the value of range is $\left[0, \max \left(0, D I_{h, t, n}+f_{h, n} / e_{h, n}\right)\right][56]$.

\subsubsection{Limits of piecewise output power}

The power output of hydro units is different as the output of hydro plants is based on the reservoirs' volume. Therefore, the limits of power related to the reservoir volume may be expressed by the following equations [56]:

$$
\begin{aligned}
& \underline{H R}_{p}(i, t)=\underline{H R}_{p}(i, s) \\
& \qquad O_{h, s-1}, \leq V O_{h}(i, t) \leq V O_{h, s}, \\
& \overline{H R}_{p}(i, t)=\min \left(H R_{p, \max }, \overline{H R}_{p}(i, s)\right), \\
& \operatorname{VO}_{h, s-1} \leq V O_{h}(i, t) \leq V O_{h, s} \\
& i \in\{1,2,3, \ldots, N H\} \text { and } s \in\{1,2,3, \ldots, S\}
\end{aligned}
$$

where $s$ indicates the piecewise water volume index within power limits [56]. $S$ is the segment number. $\underline{H R}_{p}(i, t)$ and $\overline{H R}_{p}(i, t)$ are the lower and upper limits of hydro power of unit $I$ at the $t$ th time interval [56]. $H R_{p}(i, s)$ and $\overline{H R}_{p}(i, s)$ are the lower and upper limits of power of unit $i$ at volume interval $s$ [56].

\subsubsection{Impact of water time delay}

The water time delay of flow between upstream and downstream reservoirs is influenced by outflow of water of upstream reservoir for constant natural inflow [56]. The time delay of water flow between upstream and downstream reservoirs can be shortened if water outflow of upstream reservoir increases [56]. Therefore, delay time of water flow is not constant [56]. However, 
it is found that the problems become very difficult if the non-linear function of water time delay is directly used [56]. Therefore, for maintaining the non-linear characteristics of water time delay, the non-linear function of water time delay is discretized by step function [56].

\section{Grasshopper Optimization Algorithm (GOA)}

Grasshoppers are insects that are considered as pest since they cause harm to crop production [55]. They are found individually in nature and may form a swarm of very large size [55], the unique aspect being that they can form a swarm both in nymph and adulthood [55]. In the nymph stage, they jump and move in the huge group like rolling cylinders and eat almost all vegetation, while they form a swarm in the air in adulthood. Thus, they migrate from one place to another. In the nymph stage, the movement is slow and in small steps which enhances its exploitation ability. In adulthood, long-range movement of abrupt nature is found, which enhances exploration capability of grasshoppers. Thus, exploitation and exploration are both present as natural characteristics of grasshoppers. One more important characteristic of grasshopper swarm is searching for food source [55]. The characteristics of swarming of grasshoppers have been mimicked in GOA. The mathematical model of GOA is as follows [55]:

$$
P_{i}=S o c_{i}+G_{i}+W_{i},
$$

where $P_{i}$ is the $i$ th grasshopper's position, $S_{o c}$ stands for the social interaction, $G_{i}$ denotes the force of gravity on the $i$ th grasshopper, and $W_{i}$ represents the wind advection. In order to project randomness, the equation may be represented as [55]:

$$
P_{i}=\operatorname{rand}_{1} \operatorname{Soc}_{i}+\operatorname{rand}_{2} G_{i}+\operatorname{rand}_{3} W_{i},
$$

where rand $_{1}$, rand $_{2}$, rand $_{3}$, represent random numbers in between $[0,1][55]$.

$$
\operatorname{Soc}_{i}=\sum_{\substack{j=1 \\ j \neq i}}^{N} k\left(y_{i j}\right) \hat{y}_{i j}
$$

where $y_{i j}=\left|p_{j}-p_{i}\right|$ represents the distance between the $j$ th and $i$ th grasshoppers; $\hat{y}_{i j}=\frac{p_{j}-p_{i}}{y_{i j}}$ indicates a unit vector from the $j$ th and $i$ th grasshoppers [55]; and $N$ is the number of grasshoppers. $k$ is a function defining the strength of social forces which is given by [55]:

$$
k(r)=a e^{\frac{-r}{l_{a}}}-e^{-r},
$$

where $a$ denotes the intensity of attraction and $l_{a}$ stands for the attractive length scale.

$$
G_{i}=-g y \hat{e}_{v},
$$

where $g$ indicates the gravitational constant and $\hat{e}_{v}$ represents a unity vector towards the centre of earth [55].

$$
W_{i}=u \hat{e}_{w},
$$

where $u$ indicates a constant drift and $\hat{e}_{w}$ denotes a unit vector in the wind direction [55]. Since there is no wing in nymph grasshoppers, the movement of these depends largely on the direction of wind [55].

Substituting the values of $S o c, G$, and $W$ in Eq. (17), we have:

$$
P_{i}=\sum_{\substack{j=1 \\ j \neq i}}^{N} s\left(\left|p_{j}-p_{i}\right|\right) \frac{p_{j}-p_{i}}{y_{i j}}-g d \hat{e}_{v}+u \hat{e}_{w} .
$$

However, using this mathematical model, the grasshoppers reach the comfort zone quickly and convergence of the swarm to a specific point does not occur [55]. To overcome these limitations in solving optimization problems, the equation is modified as follows [55]:

$$
P_{i}{ }^{d}=C\left(\sum_{\substack{j=1 \\ j \neq i}}^{N} C \frac{u b_{d}-l b_{d}}{2} s\left(\left|p_{j}{ }^{d}-p_{i}{ }^{d}\right|\right) \frac{p_{j}-p_{i}}{y_{i j}}\right)+\hat{T}_{d},
$$

where $u b_{d}$ is the upper bound, while $l b_{d}$ is the lower bound in the $D$ th dimension [55]. $\hat{T}_{d}$ is the value of the $D$ th dimension in the target (best solution found so far), and $C$ is a decreasing coefficient to shrink the comfort zone, repulsion zone, and attraction zone. The first $C$ in Eq. (23) balances exploration and exploitation of the entire swarm around the target. The second $C$ decreases the attraction zone, comfort zone, and repulsion zone between grasshoppers. To balance exploration and exploitation, the parameter $C$ needs to be reduced proportional to the number of iterations. This mechanism promotes exploitation with increase in iteration count. The coefficient $C$ reduces the comfort zone proportional to the number of iterations and is expressed as follows [55]:

$$
C=C_{\max }-b \frac{C_{\max }-C_{\min }}{B},
$$

where $C_{\max }$ and $C_{\min }$ denote the maximum and minimum values, respectively, $b$ is the current iteration, and $B$ represents the maximum number of iterations.

In the proposed model, the grasshoppers require moving gradually towards a target (point of convergence) during the iteration process [55]. In a real search space, the global optimum being unknown, there is no fixed target. Hence, in each step of optimization, a target needs to be found. The fittest grasshopper, i.e., the one corresponding to the best solution, is 
considered as target during the optimization process; and all the grasshoppers move towards that target in order to find a better and more accurate target in the search space. The pseudo code of GOA may be found in $[55]$.

\subsection{Algorithm}

The flowchart of GOA algorithm is explained in Figure 2 which shows the application of GOA method in HTS problems. The steps of the GOA method applied to HTS problems are given below:

1. Initialize the number of thermal and hydropower units and their specified limits. Specify the water volume limit as well as the initial and final storages of reservoir.

2. Initialize GOA parameters like $C_{\max }, C_{\min }$ and maximum iteration number.

3. Generate an initial population matrix (hydro discharges) randomly up to $(T N-1)$ interval:

$$
\begin{gathered}
D I_{h}^{T N-1}(i, t)=\left(D I_{h}^{\max }-D I_{h}^{\mathrm{min}}\right) \times \operatorname{rand}+D I_{h}^{\mathrm{min}} \\
\quad t=1,2,3, \ldots, T_{N-1} .
\end{gathered}
$$

4. Calculate volume of reservoir for each interval using hydro discharge values using Eq. (4).

5. Check the constraints limit using Eq. (5). If all constraints are satisfied, then go to step 6. Otherwise, go to step 3 .

6. Calculate the generation of hydropower for each unit using Eqs. (14) and (16).

7. Calculate the hydro discharges at $T N$ th intervals for each reservoir. The equation used to calculate discharge of $Y_{u}(i)$ number of reservoirs which do not have any upstream reservoir is given below [36]:

$$
\begin{aligned}
D I_{h}(i, t)= & V O_{h}(i, t-1) \\
& -V O_{h}(i, \text { final })+I N_{h}(i, t) .
\end{aligned}
$$

To calculate the discharge of the reservoir having a connected upstream reservoir, the following equation is used [36].

$$
\begin{aligned}
D I_{h}(i, t)= & V O_{h}(i, t-1)-V O_{h}(i, \text { final }) \\
& +I N_{h}(i, t)+\sum_{m \in Y_{u}(i)} D I_{h}\left(m, t-\tau_{m}\right) .
\end{aligned}
$$

8. Check the constraint limits of discharges of all hydro reservoirs at $T N$ th time interval. If all constraints are satisfied, then calculate the hydropower generation at $T N$ th interval using Eq. (14).

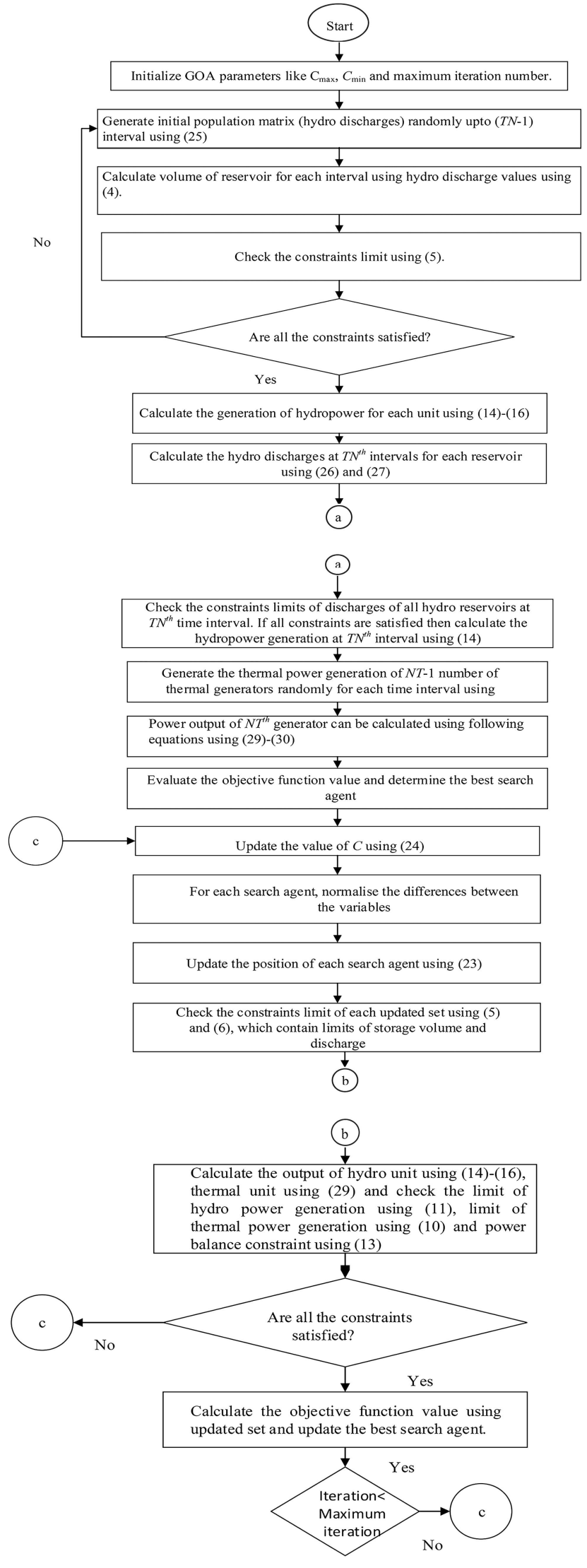

Figure 2. Flow chart of Grasshopper Optimization Algorithm (GOA) applied to Hydrothermal Scheduling (HTS) problem. 
9. Generate the thermal power generation of $N T-1$ number of thermal generators randomly for each time interval using the following equation [36]:

$$
\begin{aligned}
T H_{p}^{N T-1}(i, t)= & \left(T H_{p}^{\max }-T H_{p}^{\min }\right) \\
& \times \text { rand }+T H_{p}^{\min } .
\end{aligned}
$$

10. Power output of the NTth generator can be calculated using the following equations:

$$
\begin{aligned}
& T H_{\text {Demand }}(t)=P O_{\text {Demand }}(t)-\sum_{i=1}^{N H} H R_{p}(i, t) \\
& \text { for } t=1,2, \ldots, T N, \\
& T H_{p}^{N T}(t)=T H_{\text {Demand }}(t)-\left[\sum_{I=1}^{N T-1} T H_{p}(i, t)\right] .
\end{aligned}
$$

The decision variable matrix can be represented by:

$$
\begin{aligned}
& P= \\
& {\left[\begin{array}{c}
D I_{h}^{(1,1)} D I_{h}^{(2,1)} D I_{h}^{(3,1)} \ldots D I_{h}^{(N H, 1)} \\
D I_{h}^{(1,2)} D I_{h}^{(2,2)} D I_{h}^{(3,1)} \ldots D I_{h}^{(N H, 2)} \ldots \\
D I_{h}^{(1, T N)} D I_{h}^{(2, T N)} D I_{h}^{(3, T N)} \ldots D I_{h}^{(N H, T N)} \\
T H_{p}^{(1,1)} T H_{p}^{(2,1)} \ldots T H_{p}^{(N T, 1)} \\
T H_{p}^{(1,2)} T H_{p}^{(2,2)} \ldots T H_{p}^{(N T, 2)}
\end{array}\right]}
\end{aligned}
$$

11. Evaluate the objective function value.

12. Update the value of $C$ using Eq. (24).

13. For each search agent, normalize the differences between the variables.

14. Update the position of each search agent using Eq. (23).

15. Check the constraints limit of each updated set using Eqs. (5) and (6), which contain limits of storage volume and discharge.

16. Calculate the output of hydro unit using Eqs. (14) and (16) as well as thermal unit using Eq. (29); check the limit of hydro power generation using Eq. (11), limit of thermal power generation using Eq. (10), and power balance constraint using Eq. (13). If all constraints are satisfied, then go to step 17; otherwise, go to step 13.

17. Calculate the objective function value using updated set.

18. If the solution obtained with the updated set is better, store the updated set and the corresponding solution.

19. Repeat steps (12)-(18) until the termination criterion is reached.

\section{Simulation results}

Two test systems have been considered here in order to check the efficiency, robustness, and solution quality of GOA technique as compared to other well-known soft computing methods such as GA, BBO, DE/BBO, and GWO methods. This algorithm is tested in MATLAB 2009 and executed on a $2.4 \mathrm{GHz}$ core i3 personal computer with 2 GB RAM.

\subsection{Experimental design}

A practical test system consisting of seven hydro units and eight thermal units has been considered here. This test system is chosen because it is easier to check the feasibility of test results if a real system is considered. On the other hand, other test systems are considered to check the feasibility of the GOA algorithms as compared to other soft techniques. This algorithm is tested on small and large test systems to check whether the performance of GOA algorithm is satisfactory or not. Therefore, the main reason of choosing different test systems with different numbers of thermal and hydro units is to check the efficiency and robustness of the proposed algorithm as compared to other technique like GA, BBO, DE/BBO, and GWO.

\subsection{Description of test systems}

\subsubsection{Test system I}

Here, seven hydro and two thermal plants have been considered. Transmission loss is neglected. Input data are available in Tables A.1-A.4 in Appendix A. The optimal hourly discharges of water for each hydro plant are shown in Table 1. The hydro and thermal power generations achieved by GOA method are shown in Tables 2 and 3, respectively. The average, best, and maximum costs obtained by GOA and other optimization methods like GA, BBO, DE/BBO, and GWO are mentioned in Table 4 . Figure 3 shows the water discharges at different time intervals. The variations of reservoir volume at different time intervals by GOA algorithm are shown in Figure 4 . The power outputs of each hydro and thermal unit with variation of load at a regular time interval are shown in Figure 5. The cost convergence curves achieved by GOA, DE/BBO, BBO, GWO, and GA methods are shown in Figure 6.

\subsubsection{Test system II}

Seven hydro and four thermal plants have been considered in this case. Transmission loss is neglected. Input data are available in Tables A.1-A.4 in Appendix-A. The optimal hourly discharges of water for each hydro plant are mentioned in Table 5 . The hydro and thermal power generations achieved by GOA algorithm are shown in Tables 6 and 7 , respectively. The mean, best, and worst costs obtained by GOA and other optimization techniques like GA, BBO, DE/BBO, and GWO are described in Table 8. 
Table 1. Hourly hydro discharge obtained by Grasshopper Optimization Algorithm (GOA) algorithm for Test system I.

\begin{tabular}{|c|c|c|c|c|c|c|c|}
\hline \multirow[b]{2}{*}{ Hour } & \multicolumn{7}{|c|}{ Hydro discharges $\left(\mathrm{m}^{3}\right)$} \\
\hline & $D I_{h 1}$ & $D I_{h 2}$ & $D I_{h 3}$ & $D I_{h 4}$ & $D I_{h 5}$ & $D I_{h 6}$ & $D I_{h 7}$ \\
\hline 1 & 40492.91684 & 39397.08218 & 97339.87596 & 80750.85422 & 327337.4852 & 489492.6676 & 468758.2614 \\
\hline 2 & 28093.29614 & 34578.22238 & 237968.1313 & 127436.4753 & 358805.0142 & 577060.5733 & 264723.568 \\
\hline 3 & 39283.42062 & 33357.98934 & 167007.2547 & 89779.40675 & 265857.9057 & 627867.6063 & 393313.7155 \\
\hline 4 & 38303.43181 & 28622.07277 & 289145.4146 & 174011.1573 & 207011.3191 & 254338.7261 & 493995.1209 \\
\hline 5 & 33865.48242 & 27348.48305 & 317946.7604 & 280554.8966 & 302196.6486 & 486642.4486 & 600289.4502 \\
\hline 6 & 42040.85897 & 25232.59202 & 100110.5869 & 250599.2471 & 425452.6794 & 601353.943 & 718392.4352 \\
\hline 7 & 33362.16004 & 27130.8786 & 84603.13677 & 141677.863 & 191384.5439 & 448238.61 & 262036.3969 \\
\hline 8 & 32144.4527 & 34180.56948 & 218531.8337 & 243050.4342 & 275064.5683 & 510800.1147 & 366956.9718 \\
\hline 9 & 25004.5879 & 28598.84717 & 128183.0675 & 122984.6491 & 261418.5067 & 300675.7718 & 486437.6621 \\
\hline 10 & 32107.4448 & 25883.13269 & 318289.6232 & 326711.6211 & 413722.6835 & 518630.3465 & 360505.9557 \\
\hline 11 & 36296.5655 & 29789.68778 & 127355.8352 & 331215.0293 & 312831.8642 & 658001.109 & 328154.8499 \\
\hline 12 & 29734.23896 & 30952.69852 & 102535.2686 & 125897.1541 & 325171.8651 & 308449.7636 & 278318.6428 \\
\hline 13 & 29070.47036 & 24243.74022 & 144074.9749 & 210812.8964 & 177242.7026 & 593200.4193 & 289664.7905 \\
\hline 14 & 30380.11404 & 40583.65285 & 252605.3737 & 226291.5277 & 423997.6018 & 322287.3089 & 497197.1394 \\
\hline 15 & 44555.81211 & 37198.22025 & 213666.9677 & 202712.3944 & 158710.9667 & 444352.6154 & 500660.5803 \\
\hline 16 & 36534.26931 & 25498.8936 & 350916.3121 & 116121.2649 & 239486.8646 & 348793.3549 & 377377.7065 \\
\hline 17 & 34701.02737 & 38739.45523 & 90971.72652 & 175396.678 & 288448.1593 & 432865.5973 & 401111.8063 \\
\hline 18 & 41942.19154 & 29936.83971 & 144776.8361 & 293481.4044 & 92836.05538 & 558523.2228 & 604723.0148 \\
\hline 19 & 39467.67703 & 40492.49145 & 169735.0602 & 187677.4849 & 347254.3662 & 368205.6791 & 199008.6357 \\
\hline 20 & 29250.13918 & 32274.2464 & 245007.3438 & 329630.3315 & 428973.1089 & 535747.759 & 547030.0323 \\
\hline 21 & 28288.61849 & 22368.02485 & 345657.2454 & 260635.1185 & 197131.0163 & 436623.1178 & 284692.9706 \\
\hline 22 & 40365.87295 & 29542.63642 & 248723.7633 & 238157.1698 & 412305.4278 & 411687.3309 & 458348.5022 \\
\hline 23 & 30082.56141 & 27655.79825 & 225229.4821 & 161543.9004 & 340549.3786 & 349286.4643 & 416322.5759 \\
\hline 24 & 29913.06715 & 29913.06715 & 354656.2627 & 354656.2627 & 354656.2627 & 709427.3323 & 709427.3323 \\
\hline
\end{tabular}

Table 2. Hydro power output for Test system I against minimum cost using Grasshopper Optimization Algorithm (GOA).

\begin{tabular}{|c|c|c|c|c|c|c|c|}
\hline \multirow[b]{2}{*}{ Hour } & \multicolumn{7}{|c|}{ Hydro power output (MW) } \\
\hline & $H R_{p 1}$ & $H R_{p 2}$ & $H R_{p 3}$ & $\boldsymbol{H R}_{p 4}$ & $\boldsymbol{H R}_{p 5}$ & $\boldsymbol{H} \boldsymbol{R}_{p 6}$ & $\boldsymbol{H} \boldsymbol{R}_{p 7}$ \\
\hline 1 & 0.9673 & 0.9112 & 1.8412 & 1.2770 & 9.6634 & 13.7745 & 12.8516 \\
\hline 2 & 0.3325 & 0.6645 & 6.6240 & 2.8648 & 10.7337 & 17.6722 & 3.7700 \\
\hline 3 & 0.9054 & 0.6020 & 4.2106 & 1.5841 & 7.5725 & 19.9336 & 9.4936 \\
\hline 4 & 0.8552 & 0.3595 & 8.3645 & 4.4488 & 5.5712 & 3.3078 & 13.9749 \\
\hline 5 & 0.6280 & 0.2943 & 9.3441 & 8.0724 & 8.8084 & 13.6477 & 18.7061 \\
\hline 6 & 1.0466 & 0.1860 & 1.9355 & 7.0536 & 13.0003 & 18.7535 & 23.9628 \\
\hline 7 & 0.6022 & 0.2832 & 1.4081 & 3.3492 & 5.0397 & 11.9383 & 3.6504 \\
\hline 8 & 0.5399 & 0.6441 & 5.9630 & 6.7968 & 7.8856 & 14.7229 & 8.3205 \\
\hline 9 & 0.1743 & 0.3583 & 2.8902 & 2.7134 & 7.4215 & 5.3703 & 13.6385 \\
\hline 10 & 0.5380 & 0.2193 & 9.3557 & 9.6422 & 12.6014 & 15.0714 & 8.0333 \\
\hline 11 & 0.7525 & 0.4193 & 2.8621 & 9.7953 & 9.1701 & 21.2748 & 6.5934 \\
\hline 12 & 0.4165 & 0.4789 & 2.0179 & 2.8125 & 9.5898 & 5.7163 & 4.3752 \\
\hline 13 & 0.3825 & 0.1354 & 3.4307 & 5.7004 & 4.5587 & 18.3906 & 4.8802 \\
\hline 14 & 0.4495 & 0.9720 & 7.1218 & 6.2269 & 12.9509 & 6.3322 & 14.1174 \\
\hline 15 & 1.1753 & 0.7986 & 5.7975 & 5.4249 & 3.9285 & 11.7653 & 14.2716 \\
\hline 16 & 0.7646 & 0.1996 & 10.4654 & 2.4800 & 6.6756 & 7.5120 & 8.7843 \\
\hline 17 & 0.6708 & 0.8775 & 1.6246 & 4.4959 & 8.3408 & 11.2540 & 9.8407 \\
\hline 18 & 1.0415 & 0.4268 & 3.4546 & 8.5120 & 1.6881 & 16.8471 & 18.9034 \\
\hline 19 & 0.9148 & 0.9673 & 4.3034 & 4.9136 & 10.3408 & 8.3760 & 0.8451 \\
\hline 20 & 0.3917 & 0.5465 & 6.8634 & 9.7414 & 13.1201 & 15.8333 & 16.3355 \\
\hline 21 & 0.3425 & 0.0393 & 10.2865 & 7.3949 & 5.2351 & 11.4213 & 4.6589 \\
\hline 22 & 0.9608 & 0.4067 & 6.9898 & 6.6304 & 12.5532 & 10.3114 & 12.3883 \\
\hline 23 & 0.4343 & 0.3101 & 6.1908 & 4.0248 & 10.1128 & 7.5339 & 10.5177 \\
\hline 24 & 0.4256 & 0.4256 & 10.5926 & 10.5926 & 10.5926 & 23.5638 & 23.5638 \\
\hline
\end{tabular}


Table 3. Thermal power output for Test system I against minimum cost using Grasshopper Optimization Algorithm (GOA).

\begin{tabular}{|c|c|c|}
\hline \multirow[b]{2}{*}{ Hour } & \multicolumn{2}{|c|}{ Thermal power output (MW) } \\
\hline & $T H_{p 1}$ & $T H_{p 2}$ \\
\hline 1 & 507.5069682 & 501.2066414 \\
\hline 2 & 963.2166106 & 594.1217663 \\
\hline 3 & 1859.211511 & 596.4866667 \\
\hline 4 & 1066.274219 & 596.8437858 \\
\hline 5 & 885.9453059 & 604.5537908 \\
\hline 6 & 2767.333866 & 616.7278747 \\
\hline 7 & 1959.5627 & 514.166251 \\
\hline 8 & 1671.336756 & 583.7904157 \\
\hline 9 & 1390.339097 & 577.0942704 \\
\hline 10 & 1867.07321 & 627.4654552 \\
\hline 11 & 1852.936634 & 596.1958816 \\
\hline 12 & 1595.957601 & 578.6354243 \\
\hline 13 & 1344.202782 & 618.3187792 \\
\hline 14 & 1464.701857 & 587.1274437 \\
\hline 15 & 1622.716591 & 534.1215832 \\
\hline 16 & 1493.15729 & 619.9611817 \\
\hline 17 & 1372.463776 & 610.4317652 \\
\hline 18 & 1831.16237 & 597.9641564 \\
\hline 19 & 1903.326233 & 616.0127159 \\
\hline 20 & 1750.508942 & 586.6591074 \\
\hline 21 & 1846.824104 & 563.797408 \\
\hline 22 & 1502.237389 & 587.5220127 \\
\hline 23 & 1902.371229 & 558.5044016 \\
\hline 24 & 1858.519642 & 611.7238002 \\
\hline
\end{tabular}

Figure 7 shows the water discharges at different time intervals. The variations of reservoir volume for each time interval by GOA algorithm are depicted in Figure 8. The power outputs of each hydro and thermal unit with variation of load at a regular time interval are shown in Figure 9. The cost convergence

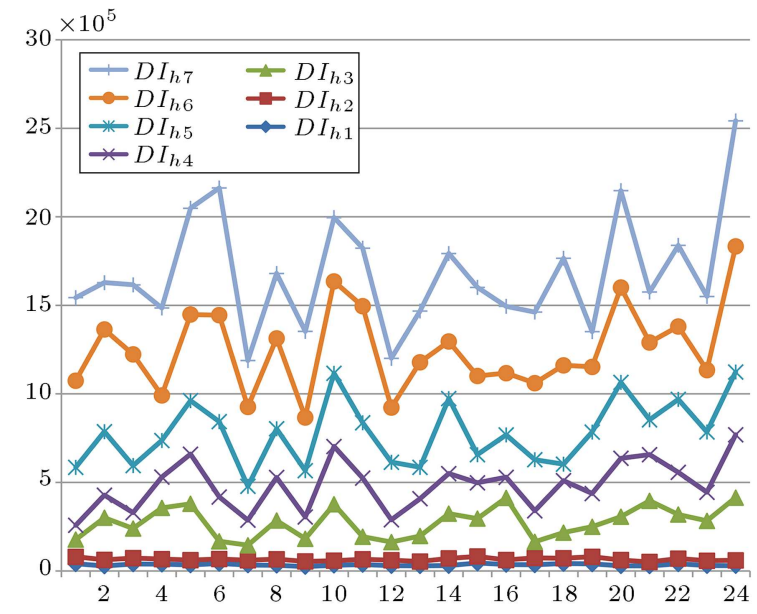

Figure 3. Hourly water discharges of different hydro plant for Test system I.

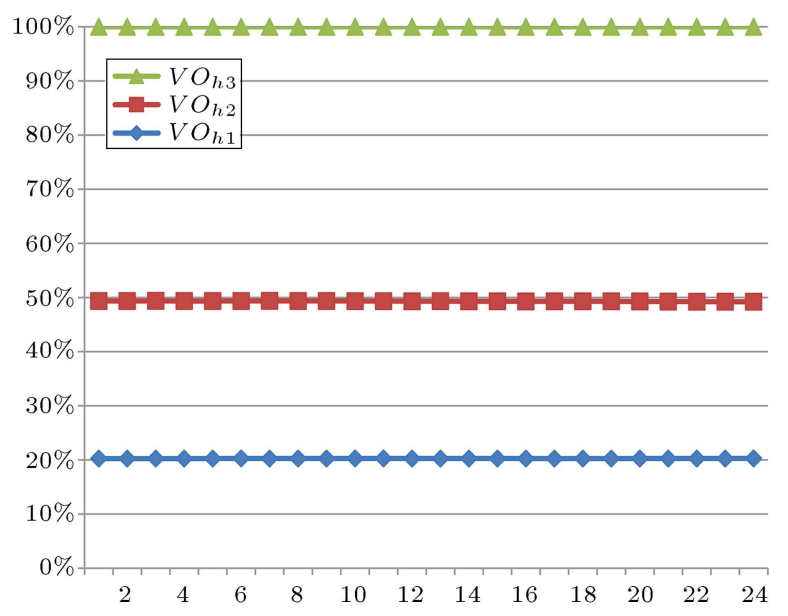

Figure 4. Variation of reservoir volume at different time intervals for Test system I.

characteristics achieved by GOA, GA, BBO, DE/BBO, and GWO methods are shown in Figure 10.

\subsubsection{Test system III}

It consists of a practical test system of India having seven hydro units and eight thermal units. Transmission loss is neglected. Input data are available in Tables A.1-A.4 in Appendix A. Table 9 shows the optimal hourly discharges of water of each hydro unit. Tables 10 and 11 describe the hydro and thermal power

Table 4. Performance analysis of different techniques taken after 50 trails.

\begin{tabular}{ccccccc}
\hline \multirow{2}{*}{ Methods } & \multicolumn{2}{c}{ Generation cost $(\$ / \mathbf{h})$} & \multirow{2}{*}{$\begin{array}{c}\text { Time } \\
\text { (s) }\end{array}$} & $\begin{array}{c}\text { No of hits to } \\
\text { minimum solution }\end{array}$ \\
\cline { 2 - 4 } & Max. & Min. & Average & & (s) & 48 \\
GOA & $\mathbf{4 8 9 0 3 6 . 3 2 2 3}$ & $\mathbf{4 8 7 1 4 2 . 7 1 1 1}$ & $\mathbf{4 8 7 2 1 8 . 4 5 5 5 4}$ & & $\mathbf{7 6}$ & 48 \\
GWO & 489343.4197 & 488500.299 & 488567.74866 & & 84 & 46 \\
DE/BBO & 490337.729 & 490083.6615 & 490103.9869 & & 97 & 46 \\
BBO & 490448.649 & 490263.7445 & 490282.23496 & & 105 & 45 \\
GA & 491405.6619 & 490853.5368 & 490941.87682 & & 115 & 42 \\
\hline
\end{tabular}


Table 5. Hourly hydro discharge obtained by Grasshopper Optimization Algorithm (GOA) algorithm for Test system-II.

\begin{tabular}{|c|c|c|c|c|c|c|c|}
\hline \multirow[b]{2}{*}{ Hour } & \multicolumn{7}{|c|}{ Hydro discharges $\left(\mathrm{m}^{3}\right)$} \\
\hline & $D I_{h 1}$ & $D I_{h 2}$ & $D I_{h 3}$ & $D I_{h 4}$ & $D I_{h 5}$ & $D I_{h 6}$ & $D I_{h 7}$ \\
\hline 1 & 33590.63793 & 34959.95673 & 197797.335 & 167635.4973 & 335844.2266 & 583707.7866 & 214022.9464 \\
\hline 2 & 25806.11954 & 25176.90201 & 218399.9328 & 342464.9957 & 436312.184 & 502540.882 & 486071.1822 \\
\hline 3 & 24702.12652 & 41539.04342 & 250000.2443 & 112172.675 & 216509.6639 & 634886.744 & 360921.5856 \\
\hline 4 & 29033.45065 & 26897.67625 & 137095.771 & 163550.7566 & 315096.8185 & 351961.1288 & 351869.24 \\
\hline 5 & 34616.25317 & 42502.08782 & 60799.25463 & 214882.8593 & 99169.04448 & 359194.4357 & 313393.3658 \\
\hline 6 & 36016.03536 & 36023.59317 & 78883.35491 & 255576.6494 & 454740.3366 & 487694.774 & 477488.3164 \\
\hline 7 & 28219.25559 & 25266.04236 & 88762.49515 & 71042.69162 & 436141.696 & 525069.88 & 262440.1915 \\
\hline 8 & 29789.23325 & 26299.79231 & 153944.1207 & 306518.4933 & 291803.1014 & 397998.3814 & 390452.0578 \\
\hline 9 & 34422.06232 & 27675.59325 & 236280.7231 & 244970.5814 & 181341.1906 & 360764.9238 & 365473.5933 \\
\hline 10 & 43046.88873 & 35782.93711 & 74617.4556 & 220387.9796 & 235585.4306 & 592509.9152 & 443514.113 \\
\hline 11 & 30909.2605 & 37132.76981 & 231125.938 & 271137.1444 & 222229.05 & 643029.149 & 527912.7631 \\
\hline 12 & 29697.7871 & 37829.60854 & 65935.30575 & 206543.2847 & 76083.27299 & 403868.3224 & 266184.1939 \\
\hline 13 & 34232.72389 & 38534.37861 & 207234.5139 & 146789.9136 & 309741.6737 & 712559.9437 & 633188.1687 \\
\hline 14 & 33091.55468 & 27014.20079 & 135942.355 & 218908.3398 & 453986.8172 & 530997.738 & 394681.4365 \\
\hline 15 & 42197.5809 & 33297.52534 & 193727.8729 & 252409.077 & 409532.4293 & 518323.1673 & 619260.4656 \\
\hline 16 & 28730.30157 & 30947.47649 & 259457.9055 & 319454.4099 & 260741.8701 & 353764.0812 & 338061.483 \\
\hline 17 & 31815.09482 & 35079.78756 & 172496.3477 & 295092.1459 & 382050.5048 & 404871.6555 & 533501.2412 \\
\hline 18 & 36667.77146 & 39544.43353 & 371264.2411 & 270057.3498 & 431162.8106 & 322300.3864 & 642754.2499 \\
\hline 19 & 36404.45013 & 43359.94421 & 293712.6911 & 113604.4611 & 288574.5465 & 641444.8267 & 360644.3517 \\
\hline 20 & 42228.42248 & 28086.10431 & 182411.8878 & 112323.3384 & 340109.3397 & 328630.4314 & 380130.9013 \\
\hline 21 & 36656.5722 & 29210.84566 & 67036.2851 & 257047.2286 & 273668.8603 & 538560.212 & 585925.74 \\
\hline 22 & 27372.43762 & 25624.76973 & 171584.599 & 153436.3154 & 467034.4592 & 520564.3892 & 400628.9643 \\
\hline 23 & 33018.68788 & 27462.81856 & 340993.6014 & 170902.5889 & 379188.6932 & 460767.3047 & 661512.6209 \\
\hline 24 & 25643.50209 & 25643.50209 & 284991.0846 & 284991.0846 & 284991.0846 & 206978.1845 & 206978.1845 \\
\hline
\end{tabular}

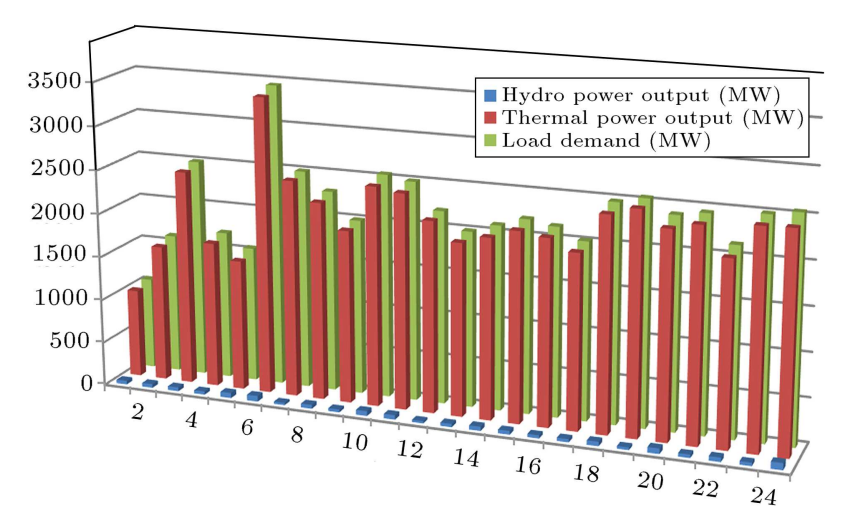

Figure 5. The hourly power generation of hydro and thermal plants with load demand for Test system I.

generations achieved by GOA algorithm, respectively. The mean, best, and worst costs obtained by GOA and other existing optimization methods like GA, BBO, $\mathrm{DE} / \mathrm{BBO}$, and GWO are shown in Table 12. Figure 11 depicts the water discharges at different time intervals. Figure 12 shows the variations of reservoir volume for each time interval by GOA algorithm. The power outputs of each hydro and thermal unit with variation of load at a regular time interval are shown in Figure 13.

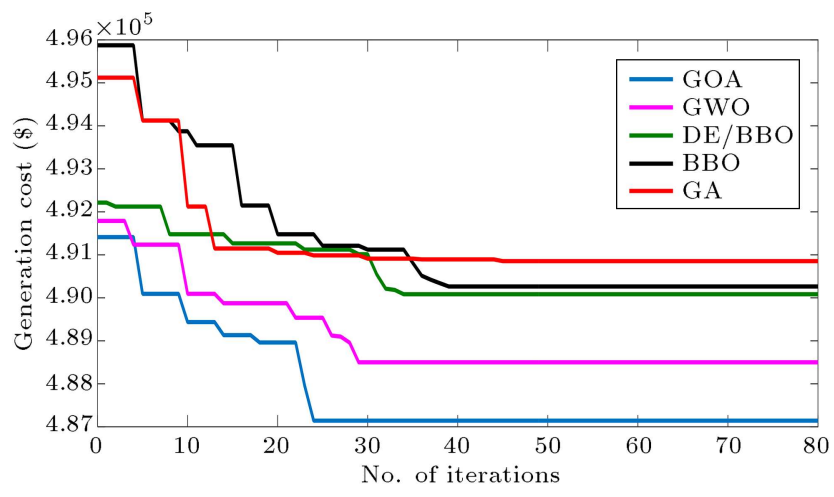

Figure 6. The convergence speed achieved by Grasshopper Optimization Algorithm (GOA), Genetic Algorithm (GA), BBO, DE/BBO, and Grey Wolf Optimizer (GWO) methods for Test system I.

The convergence speed achieved by GOA, GA, BBO, DE/ BBO, and GWO methods is shown in Figure 14.

\section{Comparative study}

\subsection{Solution quality}

The best, mean, and maximum costs obtained by GOA and other well-known methods like GA, BBO, 
Table 6. Hydropower output for Test system II against minimum cost using Grasshopper Optimization Algorithm (GOA).

\begin{tabular}{|c|c|c|c|c|c|c|c|}
\hline \multirow[b]{2}{*}{ Hour } & \multicolumn{7}{|c|}{ Hydro power output (MW) } \\
\hline & $H R_{p 1}$ & $H R_{p 2}$ & $H R_{p 3}$ & $\boldsymbol{H} \boldsymbol{R}_{p 4}$ & $H R_{p 5}$ & $H R_{p 6}$ & $H R_{p 7}$ \\
\hline 1 & 0.6139 & 0.6840 & 5.2578 & 4.2320 & 9.9528 & 17.9680 & 1.5134 \\
\hline 2 & 0.2154 & 0.1831 & 5.9585 & 10.1779 & 13.3697 & 14.3553 & 13.6222 \\
\hline 3 & 0.1588 & 1.0209 & 7.0332 & 2.3457 & 5.8942 & 20.2460 & 8.0518 \\
\hline 4 & 0.3806 & 0.2712 & 3.1933 & 4.0931 & 9.2471 & 7.6530 & 7.6489 \\
\hline 5 & 0.6664 & 1.0702 & 0.5985 & 5.8389 & 1.9034 & 7.9749 & 5.9363 \\
\hline 6 & 0.7381 & 0.7385 & 1.2135 & 7.2229 & 13.9964 & 13.6945 & 13.2402 \\
\hline 7 & 0.3389 & 0.1877 & 1.5495 & 0.9469 & 13.3639 & 15.3581 & 3.6684 \\
\hline 8 & 0.4193 & 0.2406 & 3.7663 & 8.9554 & 8.4549 & 9.7021 & 9.3662 \\
\hline 9 & 0.6565 & 0.3111 & 6.5666 & 6.8621 & 4.6981 & 8.0448 & 8.2544 \\
\hline 10 & 1.0981 & 0.7262 & 1.0684 & 6.0261 & 6.5430 & 18.3598 & 11.7280 \\
\hline 11 & 0.4766 & 0.7953 & 6.3913 & 7.7521 & 6.0887 & 20.6084 & 15.4846 \\
\hline 12 & 0.4146 & 0.8310 & 0.7732 & 5.5552 & 1.1183 & 9.9634 & 3.8351 \\
\hline 13 & 0.6468 & 0.8670 & 5.5787 & 3.5230 & 9.0650 & 23.7032 & 20.1704 \\
\hline 14 & 0.5884 & 0.2772 & 3.1541 & 5.9758 & 13.9708 & 15.6219 & 9.5545 \\
\hline 15 & 1.0546 & 0.5989 & 5.1194 & 7.1151 & 12.4589 & 15.0578 & 19.5505 \\
\hline 16 & 0.3651 & 0.4786 & 7.3549 & 9.3953 & 7.3985 & 7.7332 & 7.0343 \\
\hline 17 & 0.5230 & 0.6902 & 4.3973 & 8.5668 & 11.5242 & 10.0080 & 15.7333 \\
\hline 18 & 0.7715 & 0.9188 & 11.1574 & 7.7154 & 13.1945 & 6.3328 & 20.5962 \\
\hline 19 & 0.7580 & 1.1141 & 8.5199 & 2.3944 & 8.3451 & 20.5379 & 8.0395 \\
\hline 20 & 1.0562 & 0.3321 & 4.7345 & 2.3508 & 10.0978 & 6.6145 & 8.9068 \\
\hline 21 & 0.7709 & 0.3897 & 0.8106 & 7.2729 & 7.8382 & 15.9585 & 18.0668 \\
\hline 22 & 0.2955 & 0.2061 & 4.3663 & 3.7491 & 14.4145 & 15.1575 & 9.8192 \\
\hline 23 & 0.5846 & 0.3002 & 10.1279 & 4.3431 & 11.4269 & 12.4960 & 21.4311 \\
\hline 24 & 0.2070 & 0.2070 & 8.2232 & 8.2232 & 8.2232 & 1.1998 & 1.1998 \\
\hline
\end{tabular}

Table 7. Thermal power output for Test system II against minimum cost using Grasshopper Optimization Algorithm (GOA).

\begin{tabular}{ccccc}
\hline & \multicolumn{4}{c}{ Thermal power output (MW) } \\
\cline { 2 - 5 } Hour & $\boldsymbol{T H}_{\boldsymbol{p} \mathbf{1}}$ & $\boldsymbol{T} \boldsymbol{H}_{\boldsymbol{p} \mathbf{2}}$ & $\boldsymbol{T H}_{\boldsymbol{p} \mathbf{3}}$ & $\boldsymbol{T H}_{\boldsymbol{p 4}}$ \\
\hline 1 & 331.5562351 & 355.5824522 & 199.1407687 & 123.4986659 \\
2 & 487.8289462 & 362.2402057 & 271.8077616 & 420.2409792 \\
3 & 764.2026314 & 585.5493386 & 426.0907992 & 679.4065994 \\
4 & 587.3510344 & 443.304046 & 209.0245329 & 427.8331322 \\
5 & 584.3799821 & 358.9961824 & 208.380749 & 374.2543966 \\
6 & 1560.845923 & 600.4355873 & 498.1935373 & 739.6808604 \\
7 & 1590.698642 & 627.9307705 & 499.4284401 & 746.5288134 \\
8 & 666.0959424 & 589.375528 & 425.5218599 & 578.1017655 \\
9 & 2117.19067 & 587.7268128 & 499.7613932 & 759.9274164 \\
10 & 1663.663828 & 620.721699 & 495.4167718 & 724.6481297 \\
11 & 1685.068788 & 608.6787928 & 423.7623485 & 724.8930567 \\
12 & 2293.331546 & 629.9720884 & 498.408751 & 755.7969251 \\
13 & 2119.120912 & 597.299512 & 497.1736925 & 722.8516142 \\
14 & 2163.379694 & 627.7256077 & 499.8901828 & 759.8618974 \\
15 & 2252.597894 & 629.9992463 & 498.4203095 & 758.0273775 \\
16 & 2226.724755 & 629.7731833 & 498.8178353 & 754.9242694 \\
17 & 2117.702719 & 627.9852436 & 497.0250669 & 725.8440927 \\
18 & 1945.066927 & 619.291711 & 498.9349423 & 756.0199187 \\
19 & 1758.112509 & 598.059681 & 497.1734536 & 746.9454936 \\
20 & 1498.149164 & 617.9586667 & 498.2077264 & 751.5916483 \\
21 & 1639.412505 & 593.9741893 & 490.4597061 & 675.0460993 \\
22 & 1277.529932 & 589.4744581 & 497.8355926 & 727.1517813 \\
23 & 1034.692455 & 629.4923789 & 499.7076326 & 725.3977435 \\
24 & 1023.34016 & 607.9474022 & 465.3570154 & 725.8720295 \\
\hline
\end{tabular}


Table 8. Performance analysis of different techniques taken after 50 trails.

\begin{tabular}{ccccccc}
\hline \multirow{2}{*}{ Methods } & \multicolumn{2}{c}{ Generation cost $(\$ / \mathbf{h})$} & \multicolumn{2}{c}{$\begin{array}{c}\text { Time } \\
(\mathbf{s})\end{array}$} & $\begin{array}{c}\text { No of hits to } \\
\text { minimum solution }\end{array}$ \\
\cline { 2 - 4 } GOA & $\mathbf{6 3 7 4 9 0 . 2 6 4 5}$ & $\mathbf{6 3 7 2 7 5 . 9 8 6 6}$ & $\mathbf{6 3 7 2 8 8 . 8 4 3 2 8}$ & $\mathbf{9 6}$ & $\mathbf{4 7}$ \\
GWO & 637659.1476 & 637494.6423 & 637507.80272 & 103 & 46 \\
DE/BBO & 637946.4291 & 637659.1476 & 637687.87576 & 107 & 45 \\
BBO & 638032.6965 & 637751.256 & 637779.40004 & 111 & 45 \\
GA & 639039.6396 & 638135.6659 & 638262.22222 & 121 & 43 \\
\hline
\end{tabular}

Table 9. Hourly hydro discharge obtained by Grasshopper Optimization Algorithm (GOA) algorithm for Test system III.

\begin{tabular}{|c|c|c|c|c|c|c|c|}
\hline \multirow[b]{2}{*}{ Hour } & \multicolumn{7}{|c|}{ Hydro discharges $\times 10^{4}\left(\mathrm{~m}^{3}\right)$} \\
\hline & $D I_{h 1}$ & $D I_{h 2}$ & $D I_{h 3}$ & $D I_{h 4}$ & $D I_{h 5}$ & $D I_{h 6}$ & $D I_{h 7}$ \\
\hline 1 & 3.5368211650 & 3.1763728250 & 29.262475750 & 38.30332297 & 19.29122459 & 67.00416046 & 44.72746009 \\
\hline 2 & 3.6976109460 & 2.7794389810 & 38.085137020 & 7.882892833 & 32.57854105 & 60.09293966 & 19.42362478 \\
\hline 3 & 2.2816850280 & 3.6756712980 & 39.485973000 & 27.75753121 & 10.29109875 & 60.62033437 & 28.71988315 \\
\hline 4 & 2.1709859760 & 2.9245240720 & 36.075354060 & 10.26317213 & 8.445541715 & 30.32660957 & 54.4154159 \\
\hline 5 & 3.4734322470 & 3.3566796890 & 13.793752490 & 25.56933946 & 45.92541002 & 23.34654318 & 59.8759611 \\
\hline 6 & 3.2259009710 & 2.2119079650 & 33.632832360 & 32.29365557 & 11.24257464 & 21.37857991 & 45.2837661 \\
\hline 7 & 4.3821078370 & 4.3494269310 & 7.183928903 & 30.47729155 & 35.31032668 & 40.61766805 & 54.68712315 \\
\hline 8 & 2.2589909170 & 3.0576653800 & 29.534732250 & 5.633396442 & 27.59728204 & 30.06370152 & 28.89916402 \\
\hline 9 & 2.4443218940 & 2.4391964530 & 22.906296490 & 18.75336609 & 33.01863808 & 69.66799335 & 46.63854535 \\
\hline 10 & 2.9568352770 & 3.7195960310 & 37.047680140 & 21.86465339 & 28.24902173 & 50.367009 & 60.69541845 \\
\hline 11 & 3.4078772150 & 4.0652190180 & 38.678428220 & 25.40126712 & 6.315070488 & 54.85852694 & 36.95667551 \\
\hline 12 & 3.9110831480 & 2.5238307130 & 23.263800670 & 5.919546187 & 20.82587812 & 41.18530017 & 22.03537932 \\
\hline 13 & 4.2740941080 & 3.8723816960 & 35.389249920 & 35.98777484 & 16.90872133 & 20.80049455 & 53.86007378 \\
\hline 14 & 4.1183008190 & 3.1362169080 & 6.708170680 & 22.85315054 & 16.27184379 & 28.28534144 & 27.80748501 \\
\hline 15 & 3.0165848400 & 2.2296545040 & 7.469863973 & 21.68019224 & 34.73894743 & 71.38885664 & 18.12890624 \\
\hline 16 & 3.4016508450 & 3.2086292880 & 6.032220216 & 27.26944929 & 8.433135705 & 74.16000000 & 67.68749854 \\
\hline 17 & 4.4346357930 & 3.6251419470 & 21.303268390 & 34.20608508 & 9.592988643 & 42.14047974 & 49.23619612 \\
\hline 18 & 2.1908849570 & 3.0010776350 & 19.029953670 & 24.88983595 & 38.13043806 & 58.30840265 & 47.94846527 \\
\hline 19 & 4.2896153180 & 2.6177255510 & 36.821535530 & 8.473883987 & 47.47740258 & 51.30050953 & 52.34709442 \\
\hline 20 & 3.6502778430 & 2.8706619150 & 14.419176890 & 14.32501509 & 11.29831733 & 33.66277424 & 72.07566343 \\
\hline 21 & 2.2899633980 & 3.6366166510 & 10.181515320 & 18.86592357 & 36.53061576 & 35.48639422 & 40.78413521 \\
\hline 22 & 2.3397321280 & 3.6280992130 & 27.007145980 & 32.64016413 & 41.62873587 & 35.86225185 & 44.69641044 \\
\hline 23 & 2.6845184380 & 3.5401750180 & 37.468298580 & 26.32772287 & 10.27747272 & 24.90933657 & 64.26298172 \\
\hline 24 & 4.3980896060 & 4.3980896060 & 26.497548620 & 26.49754862 & 26.49754862 & 46.48623262 & 46.48623262 \\
\hline
\end{tabular}




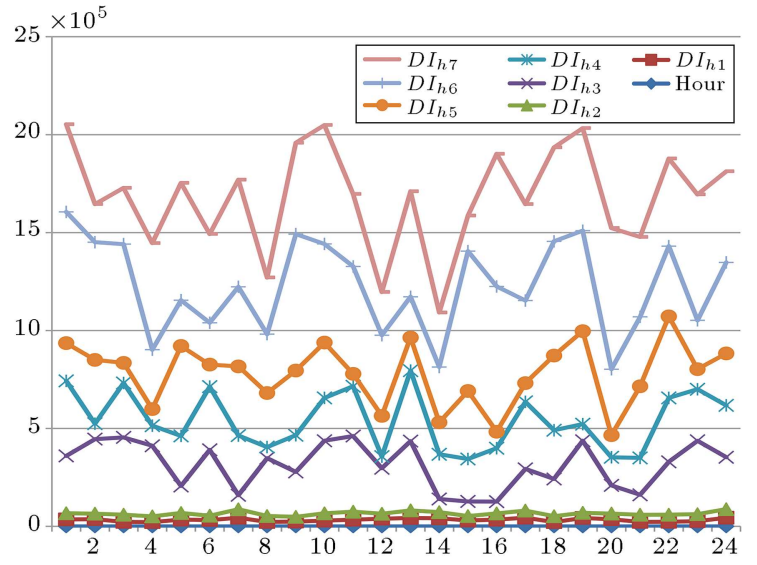

Figure 7. Hourly water discharges of different hydro plants for Test system II.

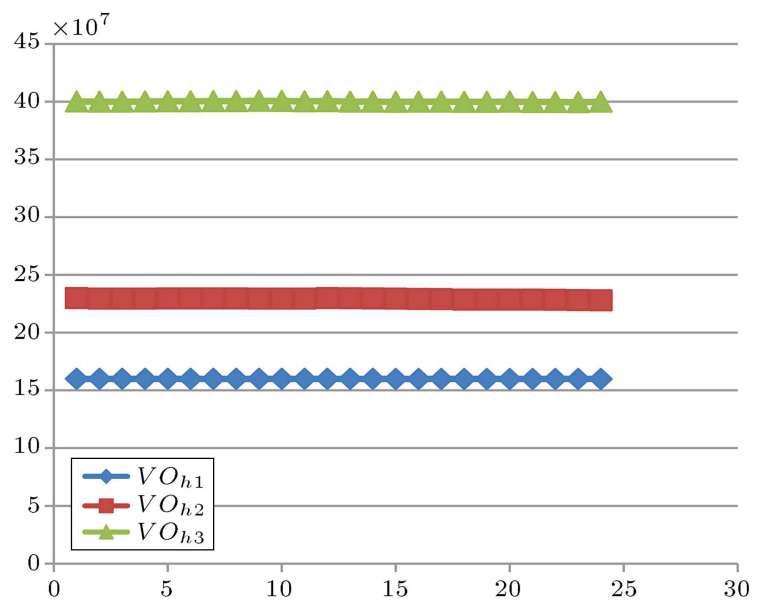

Figure 8. Variation in reservoir volumes at different time intervals for Test system II.

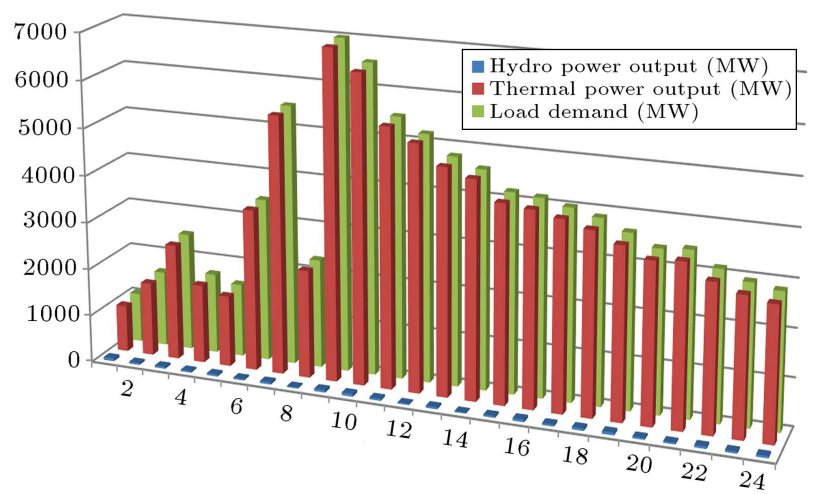

Figure 9. The hourly power generation of hydro and thermal plants with load demand for Test system II.

DE/BBO, and GWO are shown in Tables 4, 8, and 12, respectively. From these tables, it is clear that the cost obtained by GOA method is lower than the other wellknown methods. For example, in Test system I, the cost obtained by GOA technique is $487142.7111 \$ / \mathrm{h}$, whereas the costs obtained by GA, BBO, DE/BBO,

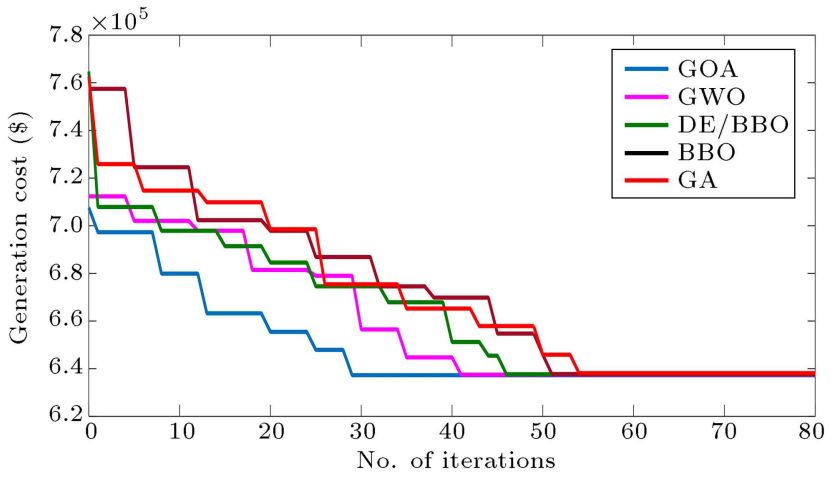

Figure 10. The convergence speed achieved by Grasshopper Optimization Algorithm (GOA), Genetic Algorithm (GA), BBO, DE/BBO, and Grey Wolf Optimizer (GWO) methods for Test system II.

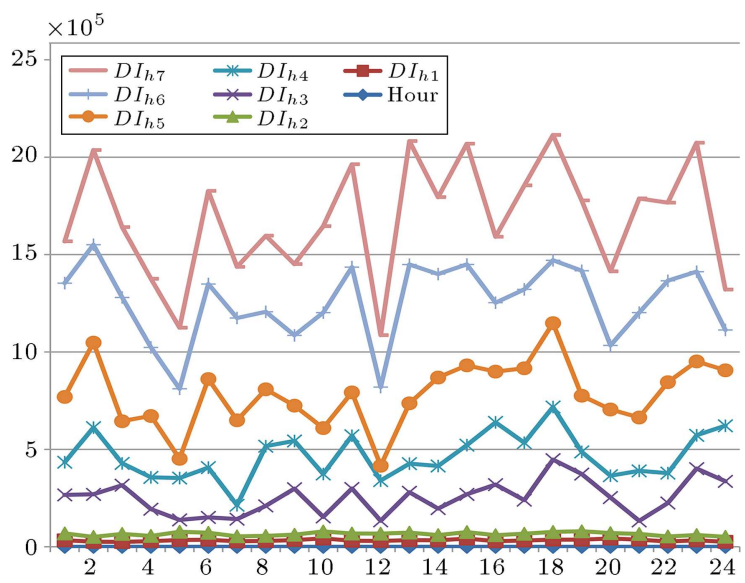

Figure 11. Hourly water discharges of different hydro plants for Test system III.

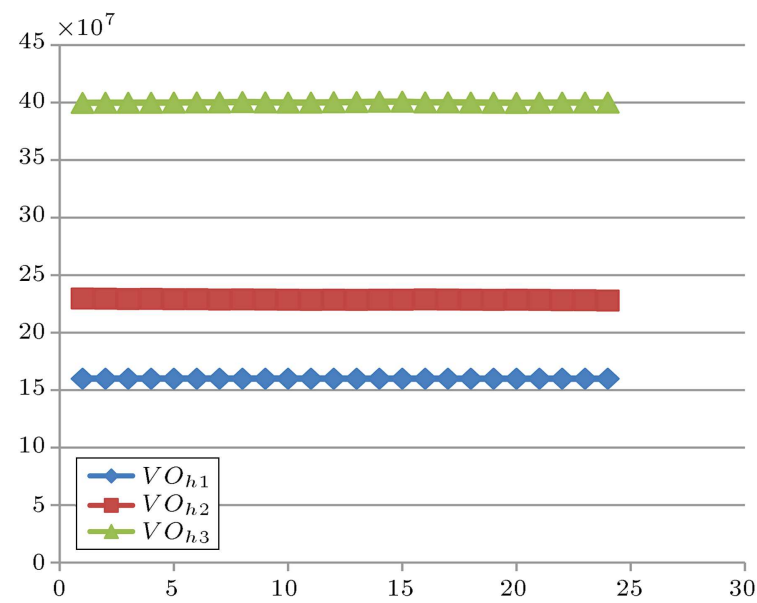

Figure 12. Variation of reservoir volume at different time intervals for Test system III.

and GWO are 490853.5368 $\$ / \mathrm{h}, 490263.7445 \$ / \mathrm{h}$, $490083.6615 \$ / \mathrm{h}$, and $488500.299 \$ / \mathrm{h}$, respectively. Same results were observed for the Test systems II and III. Therefore, these results show the capability of GOA 
Table 10. Hydropower output for Test system III against minimum cost using Grasshopper Optimization Algorithm (GOA).

\begin{tabular}{|c|c|c|c|c|c|c|c|}
\hline \multirow[b]{2}{*}{ Hour } & \multicolumn{7}{|c|}{ Hydro power output (MW) } \\
\hline & $H \boldsymbol{R}_{p 1}$ & $H R_{p 2}$ & $\boldsymbol{H} \boldsymbol{R}_{p 3}$ & $\boldsymbol{H R}_{p 4}$ & $H \boldsymbol{R}_{p 5}$ & $H R_{p 6}$ & $\boldsymbol{H R}_{p 7}$ \\
\hline 1 & 0.7049 & 0.5204 & 8.4829 & 11.5577 & 5.0916 & 21.8108 & 11.8954 \\
\hline 2 & 0.7873 & 0.3172 & 11.4835 & 1.2117 & 9.6107 & 18.7346 & 0.6327 \\
\hline 3 & 0.0623 & 0.7760 & 11.9599 & 7.9710 & 2.0307 & 18.9693 & 4.7704 \\
\hline 4 & 0.0056 & 0.3914 & 10.7999 & 2.0212 & 1.4030 & 5.4856 & 16.2075 \\
\hline 5 & 0.6725 & 0.6127 & 3.2220 & 7.2268 & 14.1499 & 2.3787 & 18.6380 \\
\hline 6 & 0.5457 & 0.0266 & 9.9692 & 9.5138 & 2.3543 & 1.5028 & 12.1430 \\
\hline 7 & 1.1377 & 1.1210 & 0.9740 & 8.8960 & 10.5397 & 10.0661 & 16.3284 \\
\hline 8 & 0.0507 & 0.4596 & 8.5755 & 0.4466 & 7.9165 & 5.3686 & 4.8502 \\
\hline 9 & 0.1456 & 0.1429 & 6.3211 & 4.9087 & 9.7603 & 22.9964 & 12.7460 \\
\hline 10 & 0.4080 & 0.7985 & 11.1306 & 5.9669 & 8.1382 & 14.4056 & 19.0027 \\
\hline 11 & 0.6389 & 0.9755 & 11.6852 & 7.1697 & 0.6785 & 16.4047 & 8.4366 \\
\hline 12 & 0.8966 & 0.1863 & 6.4427 & 0.5439 & 5.6136 & 10.3188 & 1.7951 \\
\hline 13 & 1.0824 & 0.8767 & 10.5666 & 10.7701 & 4.2814 & 1.2455 & 15.9603 \\
\hline 14 & 1.0027 & 0.4998 & 0.8121 & 6.3031 & 4.0648 & 4.5770 & 4.3643 \\
\hline 15 & 0.4386 & 0.0357 & 1.0712 & 5.9041 & 10.3454 & 23.7624 & 0.0564 \\
\hline 16 & 0.6357 & 0.5369 & 0.5823 & 7.8050 & 1.3988 & 24.9958 & 22.1149 \\
\hline 17 & 1.1646 & 0.7502 & 5.7759 & 10.1642 & 1.7933 & 10.7439 & 13.9022 \\
\hline 18 & 0.0158 & 0.4306 & 5.0028 & 6.9957 & 11.4989 & 17.9403 & 13.3291 \\
\hline 19 & 1.0904 & 0.2344 & 11.0537 & 1.4127 & 14.6778 & 14.8211 & 15.2869 \\
\hline 20 & 0.7630 & 0.3639 & 3.4347 & 3.4026 & 2.3733 & 6.9705 & 24.0681 \\
\hline 21 & 0.0665 & 0.7560 & 1.9934 & 4.9470 & 10.9548 & 7.7822 & 10.1402 \\
\hline 22 & 0.0920 & 0.7517 & 7.7158 & 9.6316 & 12.6886 & 7.9495 & 11.8816 \\
\hline 23 & 0.2686 & 0.7066 & 11.2737 & 7.4848 & 2.0261 & 3.0743 & 20.5907 \\
\hline 24 & 1.1459 & 1.1459 & 7.5425 & 7.5425 & 7.5425 & 12.6782 & 12.6782 \\
\hline
\end{tabular}

method to produce a quality solution in a consistent manner.

\subsection{Robustness}

The program was run for 50 trials in order to check the robustness of this GOA algorithm. The success rates of this GOA algorithm and other existing methods like GA, BBO, DE/BBO, and GWO are presented in Tables 4, 8, and 12, respectively. It was found that out of 50 trails, GOA hit the best solution 48 times for Test system I, 47 times for Test system II, and 50 times

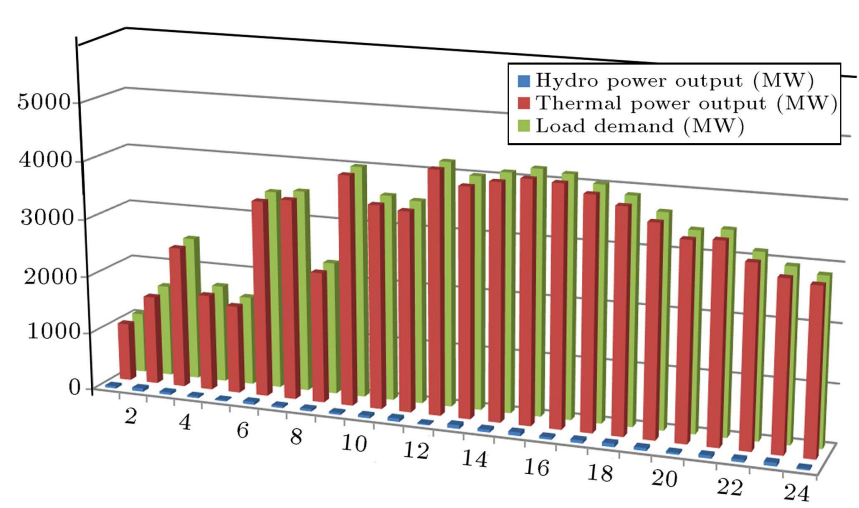

Figure 13. The hourly power generation of hydro and thermal plants with load demand for Test system III. for Test system III. Thus, the success rate achieved by GOA is $96 \%, 94 \%$, and $100 \%$, respectively. In Test system I, out of 50 trails, GA, BBO, DE/BBO, and GWO hit the best solution 42 times, 45 times, 46 times, and 46 times, respectively. In Test case II, the success rates achieved by $\mathrm{GA}, \mathrm{BBO}, \mathrm{DE} / \mathrm{BBO}$, and $\mathrm{GWO}$ are $84 \%, 88 \%, 90 \%$, and $92 \%$, respectively. For Test system II, the success rates achieved by GA, BBO, DE/BBO, and GWO are $84 \%, 90 \%, 92 \%$, and $92 \%$, respectively.

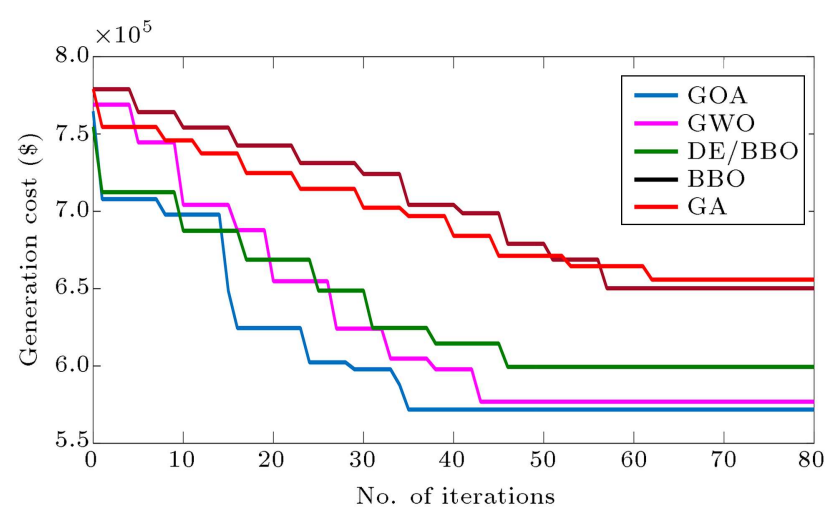

Figure 14. The convergence speed achieved by Grasshopper Optimization Algorithm (GOA), Genetic Algorithm (GA), BBO, DE/BBO, and Grey Wolf Optimizer (GWO) methods for the Test system III. 
Table 11. Thermal power output for Test system III against minimum cost using Grasshopper Optimization Algorithm (GOA).

\begin{tabular}{|c|c|c|c|c|c|c|c|c|}
\hline \multirow[b]{2}{*}{ Hour } & \multicolumn{8}{|c|}{ Thermal power output (MW) } \\
\hline & $T H_{p 1} \times 10^{3}$ & $T H_{p 2}$ & $T H_{p 3}$ & $T H_{p 4}$ & $T H_{p 5} \times 10^{3}$ & $T H_{p 6}$ & $T H_{p 7} \times 10^{3}$ & $T H_{p 8}$ \\
\hline 1 & 0.2343 & 134.3742 & 50.2022 & 123.4190 & 0.1001 & 69.4255 & 0.1580 & 120.2311 \\
\hline 2 & 0.2358 & 252.2844 & 296.0397 & 221.5022 & 0.1067 & 167.9139 & 0.1561 & 120.8922 \\
\hline 3 & 0.4179 & 585.1301 & 297.1132 & 380.3054 & 0.2981 & 206.2271 & 0.1479 & 120.7977 \\
\hline 4 & 0.2340 & 213.4500 & 146.8695 & 178.7985 & 0.2127 & 209.2651 & 0.3485 & 120.1005 \\
\hline 5 & 0.3190 & 358.6061 & 126.4816 & 132.9660 & 0.2106 & 73.2203 & 0.1597 & 122.5848 \\
\hline 6 & 0.5333 & 512.2726 & 296.6516 & 605.1446 & 0.6985 & 185.4223 & 0.4557 & 126.9647 \\
\hline 7 & 1.3114 & 629.8930 & 499.9453 & 742.0415 & 0.9476 & 209.9568 & 0.9899 & 120.1079 \\
\hline 8 & 0.3454 & 494.7274 & 203.0334 & 335.4770 & 0.3082 & 177.5198 & 0.2866 & 121.3642 \\
\hline 9 & 2.3400 & 630.0000 & 500.0000 & 760.0000 & 1.0000 & 210.0000 & 1.0000 & 502.9790 \\
\hline 10 & 2.2835 & 629.9980 & 499.9601 & 759.9879 & 0.9976 & 209.9979 & 0.9891 & 120.0118 \\
\hline 11 & 1.2472 & 629.9930 & 499.5426 & 759.9074 & 0.9991 & 209.1568 & 0.9889 & 120.1772 \\
\hline 12 & 1.0422 & 618.9608 & 499.0553 & 759.9557 & 0.9977 & 207.5712 & 0.9285 & 120.2426 \\
\hline 13 & 0.9572 & 594.6443 & 498.0779 & 727.0368 & 0.9517 & 209.9996 & 0.6957 & 120.8315 \\
\hline 14 & 0.9570 & 628.3121 & 499.9847 & 733.7249 & 0.8013 & 170.1067 & 0.6642 & 123.7046 \\
\hline 15 & 0.7448 & 591.0216 & 497.2501 & 717.3184 & 0.6401 & 209.5537 & 0.6335 & 124.7802 \\
\hline 16 & 0.6823 & 626.5212 & 495.7070 & 708.7341 & 0.7854 & 209.9665 & 0.4546 & 128.6981 \\
\hline 17 & 0.7717 & 590.4466 & 499.9948 & 722.8798 & 0.5944 & 209.8070 & 0.4630 & 123.5245 \\
\hline 18 & 0.6777 & 585.3046 & 492.3081 & 629.4499 & 0.6682 & 197.1005 & 0.4536 & 121.1592 \\
\hline 19 & 0.6900 & 566.8618 & 428.3938 & 618.9922 & 0.6458 & 174.2474 & 0.3432 & 123.8094 \\
\hline 20 & 0.5883 & 627.7235 & 356.0904 & 441.4742 & 0.6098 & 208.9371 & 0.4033 & 122.9804 \\
\hline 21 & 0.6750 & 596.7715 & 498.8828 & 567.5745 & 0.3996 & 160.1511 & 0.3925 & 122.9196 \\
\hline 22 & 0.4905 & 589.6218 & 499.9925 & 437.3202 & 0.4933 & 169.7698 & 0.2852 & 123.5080 \\
\hline 23 & 0.5986 & 592.7626 & 335.2046 & 381.8242 & 0.4490 & 154.5224 & 0.2653 & 127.3867 \\
\hline 24 & 0.5033 & 619.0501 & 290.4074 & 416.7887 & 0.3047 & 209.8466 & 0.3339 & 121.8389 \\
\hline
\end{tabular}

Table 12. Performance analysis of different techniques taken after 50 trails.

\begin{tabular}{|c|c|c|c|c|c|}
\hline \multirow{2}{*}{ Methods } & \multicolumn{3}{|c|}{ Generation cost $(\$ / h)$} & \multirow{2}{*}{$\begin{array}{c}\text { Time } \\
(\mathrm{s})\end{array}$} & \multirow{2}{*}{$\begin{array}{l}\text { No of hits to } \\
\text { minimum solution }\end{array}$} \\
\hline & Max. & Min. & Average & & \\
\hline GOA & 571827.2513 & 571827.2513 & 571827.2513 & 110 & 50 \\
\hline GWO & 581496.0532 & 576893.669 & 577445.955 & 116 & 46 \\
\hline $\mathrm{DE} / \mathrm{BBO}$ & 621234.541 & 599396.832 & 602890.865 & 121 & 45 \\
\hline $\mathrm{BBO}$ & 650898.569 & 650250.061 & 650327.881 & 127 & 44 \\
\hline GA & 659735.086 & 655835.563 & 656459.486 & 135 & 42 \\
\hline
\end{tabular}

Therefore, it is observed that the consistency of GOA method is better than other soft computing techniques.

\subsection{Computational efficiency}

The time taken for GOA algorithm to reach the best solution is shorter than those for other methods such as GA, BBO, DE/BBO, and GWO. The simulation time obtained by GOA, GA, BBO, DE/BBO, and GWO algorithm is depicted in Table 4, 8, and 12, respectively. From Table 4, it is realized that the time obtained by GOA method is 76 seconds, whereas the times obtained by GA, BBO, DE/BBO, and GWO are 115, 108, 97, and 84 seconds, respectively. The similar results are found when this GOA method is applied to the other two test systems. Therefore, it is clear that the computational efficiency of GOA algorithm is higher than that of other popular soft techniques.

It is found that the total number of iterations required to reach the best solution is less than other algorithms like GA, BBO, DE/BBO, and GWO. In Test system I, the iterations required to achieve the best solution is less in case of GOA technique among other popular soft computing methods. From Figure 6, it is seen that the number of iterations required to attain the best solution is only 25 , whereas the iterations required to achieve the best result is 46 for GA, 40 for $\mathrm{BBO}, 35$ for $\mathrm{DE} / \mathrm{BBO}$, and 30 for GWO. In the test case II, the iterations required to reach the 
Table 13. Effect of intensity of attraction (a) on Grasshopper Optimization Algorithm (GOA).

\begin{tabular}{ccccc}
\hline $\begin{array}{c}\text { Attraction } \\
\text { length }\left(\boldsymbol{l}_{\boldsymbol{a}}\right)\end{array}$ & $\begin{array}{c}\text { Intensity of } \\
\text { attraction }(\boldsymbol{a})\end{array}$ & $\begin{array}{c}\text { Test system } \\
\mathbf{I}\end{array}$ & $\begin{array}{c}\text { Test system } \\
\text { II }\end{array}$ & $\begin{array}{c}\text { Test system } \\
\text { III }\end{array}$ \\
\hline & $a=0.1$ & 491432.2008 & 652147.2369 & 602147.2813 \\
& $a=0.2$ & 490923.1237 & 646214.3087 & 594127.3615 \\
& $a=0.3$ & 489614.3389 & 639874.4123 & 587521.3914 \\
$l_{a}=1.5$ & $a=0.4$ & 489213.2591 & 638814.3693 & 587323.6614 \\
& $\boldsymbol{a}=\mathbf{0 . 5}$ & $\mathbf{4 8 7 1 4 2 . 7 1 1 1}$ & $\mathbf{6 3 7 2 7 5 . 9 8 6 6}$ & $\mathbf{5 7 1 8 2 7 . 2 5 1 3}$ \\
& $a=0.6$ & 487812.3398 & 642141.0236 & 587412.3258 \\
& $a=0.7$ & 487423.1103 & 638741.1169 & 589217.3887 \\
& $a=0.8$ & 487949.3614 & 649871.2522 & 593742.6985 \\
& $a=0.9$ & 490021.3698 & 638821.4569 & 578798.3244 \\
$a$ & $=1.0$ & 490012.7456 & 637989.2147 & 589465.2746 \\
\hline
\end{tabular}

Table 14. Effect of population size.

\begin{tabular}{cccc}
\hline Swarm size & Test system I & Test system II & Test system III \\
\hline 5 & 491774.2314 & 665487.3314 & 614756.5813 \\
10 & 490914.3229 & 651423.3685 & 601232.4789 \\
20 & 489561.7698 & 641124.1235 & 583678.3793 \\
$\mathbf{3 0}$ & $\mathbf{4 8 7 1 4 2 . 7 1 1 1}$ & $\mathbf{6 3 7 2 7 5 . 9 8 6 6}$ & $\mathbf{5 7 1 8 2 7 . 2 5 1 3}$ \\
40 & 489652.1147 & 648793.2014 & 593214.3698 \\
50 & 490096.1299 & 654141.8745 & 592214.3621 \\
60 & 491125.9813 & 659785.3477 & 601452.3049 \\
\hline
\end{tabular}

best result is 30 for GOA, 55 for GA, 52 for BBO, 47 for DE/BBO, and 42 for GWO. In the test case III, the iterations required to reach the best result is 37 for GOA, 63 for GA, 58 for BBO, 47 for DE/BBO, and 44 for GWO. Therefore, the convergence rate of GOA technique is found to be faster than that of other optimization techniques.

\subsection{Parameter tuning and effect of population size}

In case of the optimization process, appropriate tuning of control parameter is a very crucial task. In this paper, two control parameters including attraction length $\left(l_{a}\right)$ and intensity of attraction $(a)$ are chosen to demonstrate the performance of the GOA method. Table 13 describes the results obtained by GOA method according to the variation in the intensity of attraction (a). It was found that the result was obtained with $l_{a}=1.5$ and $a=0.5$ at best for all test systems. The effect of swarm size (population size) was observed for running GOA algorithm for 50 individual trails with swarm sizes of $5,10,20,30,40,50$, and 60 . The simulation results obtained by GOA technique for different swarm sizes are depicted in Table 14. It was observed that GOA yielded the best result for all test systems when the swarm size 30 is chosen. In addition, it was found that the performance of GOA method did not improve when swarm size was set above or below 30 .

\subsection{Statistical analysis}

A variety of statistical methods $[59,60]$ have so far been in use to conduct a comparative analysis of algorithms. In the present paper, comparative analyses of performances of GOA algorithms were carried out statistically through Friedman test and Quade test $[36,59,60]$. For performing Friedman test and Quade test, a null hypothesis $\left(H_{0}\right)$ was employed. $H_{0}$ indicates that there is no difference between the methods in terms of performance in comparison [36], and an alternative hypothesis $\left(H_{1}\right)$ signifying difference in their performances needs to be defined. A $5 \%$ significance level is fixed. The statistical analyses of the results obtained by using GOA, GWO, DE/BBO, $\mathrm{BBO}$, and GA algorithms are presented in Table 15. The F-statistic (Chi-Square) value, given in Table 15,

Table 15. Ranks achieved by Friedman and Quade tests for Test systems I, II, and III. The statistical computed and related $p$-values are also shown.

\begin{tabular}{|c|c|c|c|c|c|c|c|c|c|c|c|}
\hline \multicolumn{6}{|c|}{ Friedman test } & \multicolumn{6}{|c|}{ Quade test } \\
\hline Test systems & GOA & GWO & DE/BBO & $\mathrm{BBO}$ & GA & Test systems & GOA & GWO & $\mathrm{DE} / \mathrm{BBO}$ & BBO & GA \\
\hline & 1 & 2 & 3 & 4 & 5 & Test system I & -4 & -2 & 0 & 2 & 4 \\
\hline Test system I & 1 & 2 & 3 & 4 & 5 & Test system II & -2 & -1 & 0 & 1 & 2 \\
\hline Test system II & 1 & 2 & 3 & 4 & 5 & Test system III & -6 & -3 & 0 & 36 & \\
\hline Statistic & & & 12 & & & Statistic & & & 12 & & \\
\hline$p$-value & & & 0.0174 & & & $p$-value & & & 0.0018 & & \\
\hline
\end{tabular}


Table 16. Average errors obtained in Test systems I and II.

\begin{tabular}{cccccc}
\hline Test systems & GOA & GWO & DE/BBO & BBO & GA \\
\hline Test system I & 75.74444 & 1425.03756 & 2961.2758 & 3139.52386 & 3799.16572 \\
Test system II & 12.85668 & 231.81612 & 411.88916 & 503.41344 & 986.23562 \\
Test system III & 0 & 5618.7037 & 31063.6137 & 78500.6297 & 84632.2347 \\
\hline
\end{tabular}

is 12 and Q-statistic value is 12 . Thus, the F-statistic value and Q-statistic value are found to be greater than their corresponding critical values in both of the above cases. The $p$-values procured from Friedman test and Quade test turned out to be lower than those at a $5 \%$ significance level. This leads to the rejection of the null hypothesis which, in turn, signifies a remarkable difference in the performance between the algorithms. Table 16 exhibits the average errors of various techniques.

The calculation of average errors was carried out in the following steps: First, the least value among all the algorithms for each test system was found. Next, the least value was subtracted from the mean value obtained by each algorithm. Finally, all algorithms were arranged rank-wise based on the value of average error. Thus, the algorithms were ranked based on the average errors, as shown in Table 15. As seen from the tables, GOA algorithm attains the lowest rank, which indicates the better performance of GOA. Thus, it may be concluded that GOA algorithm gives a better quality solution in comparison to other recently developed optimization techniques.

\section{Conclusion}

In this paper, Grasshopper Optimization Algorithm (GOA) [55] was used for solving the short-term Hydrothermal Scheduling (HTS) problem. The variable nature of water transportation delay [58] was introduced here. The hydropower generation was calculated based on the volume segment of water. To examine the feasibility, computational efficiency, and consistency of GOA algorithm, two different test systems were considered. The results obtained by GOA method were compared with those by other optimization methods such as Grey Wolf Optimizer (GWO), DE/BBO, $\mathrm{BBO}$, and Genetic Algorithm (GA). The proposed optimization technique was found superior to other well-established techniques of optimization in terms of computational time, consistency, and solution quality. Therefore, this technique may be applied to find the solution to different complex optimization problems.

\section{References}

1. Engles, L., Larson, R.E., Peschon, J., et al. "Dynamic programming applied to hydro and thermal gener- ation scheduling", In: IEEE Tutorial Course Text, 76CH1107-2-PWR, IEEE, New York (1976).

2. Wood, J. and Wollenberg, B.F., Power Generation, Operation, and Control, John Wiley and Sons, 2nd edition, Wiley New York (1984).

3. Saha, T.N. and Khaparde, S.A. "An application of a direct method to the optimal scheduling of hydrothermal systems", IEEE Trans PAS, 97(3), pp. 977-983 (1978).

4. Rashid, AHA. and Nor, K.M. "An efficient method for optimal scheduling of fixed head hydro and thermal plants", IEEE Trans Power Syst, 6(2), pp. 632-636 (1991).

5. Nilsson, O. and Sjelvgren, D. "Mixed-integer programming applied to short-term planning of a hydrothermal system", IEEE Trans Power Syst, 11(1), pp. 281-286 (1996).

6. Wong, K.P. and Wong, Y.W. "Short-term hydrothermal scheduling Part I: simulated annealing approach", Proc Inst Electr Eng Gen Transm Distrib., 141(5), pp. 497-501 (1994).

7. Wong, K.P. and Wong, Y.W. "Short-term hydrothermal scheduling Part II: parallel simulated annealing approach", Proc Inst Electr Eng Gen Transm Distrib, 141(5), pp. 502-506 (1994).

8. Chen, PO-H. and Chang, H.C. "Genetic aided scheduling of hydraulically coupled plants in hydrothermal coordination", IEEE Trans Power Syst, 11(2), pp. 975-981 (1996).

9. Orero, S.O. and Irving, M.R. "A genetic algorithm modeling framework and solution technique for short term optimal hydrothermal scheduling", IEEE Trans PWRS, 13 (2), pp. 501-518 (1998).

10. Gil, E., Bustos, J., and Rudnick, H. "Short-term hydro thermal generation scheduling model using a genetic algorithm", IEEE Trans PWRS, 18(4), pp. 1256-1264 (2003).

11. Kumar, S. and Naresh, R. "Efficient real coded genetic algorithm to solve the non-convex hydrothermal scheduling problem", Int J Elec Power and Energ Sys, 29(10), pp. 738-747 (2007).

12. Hota, P.K., Chakrabarti, R., and Chattopadhyay, P.K. "Short-term hydrothermal scheduling through evolutionary programming technique", Electr Power Syst Res., 52, pp. 189-196 (1999). 
13. Sinha, N., Chakrabarti, R., and Chattopadhyay, P.K. "Fast evolutionary programming techniques for shortterm hydrothermal scheduling", Electric Power Syst Res., 66, pp. 97-103 (2003).

14. Mandal, K.K., Basu, M., and Chakraborty, N. "Particle swarm optimization technique based short-term hydrothermal scheduling", Appl Soft Comput, 8, pp. 1392-1399 (2008).

15. Wang, Y., Zhou, J., Zhou, C., et al. "An improved selfadaptive PSO technique for short-term hydrothermal scheduling", Expert Sys with Appl, 39, pp. 2288-2295 (2012).

16. Cavazzini, G., Pavesi, G., and Ardizzon, G. "A novel two-swarm based PSO search strategy for optimal short-term hydro-thermal generation scheduling", Energ Conv and Mang, 164, pp. 460-481 (2018).

17. Mandal, K.K. and Chakraborty, N. "Differential evolution technique-based short-term economic generation scheduling of hydrothermal systems", Electr Power Syst Res., 78(11), pp. 1972-1979 (2008).

18. Sivansubramani, S. and Swarup, K.S. "Hybrid DESQP algorithm for non-convex short term hydrothermal scheduling problem", Energ Conv and Mang., 52, pp. 757-761 (2011).

19. Basu, M. "Improved differential evolution for shortterm hydrothermal scheduling", Elec Power \& Energ., 58, pp. 91-100 (2014).

20. Basu, M. "Hopfield neural networks for optimal scheduling of fixed head hydrothermal power systems", Electr Power Syst Res., 64(1), pp. 11-15 (2003).

21. Roy, P.K. "Teaching learning based optimization for short term hydrothermal scheduling problem considering valve point effect and prohibited discharge constraint", Int J Elec Power and Energ Sys., 53, pp. 10-19 (2013).

22. Roy, P.K., Paul, C., and Sultana, S. "Oppositional teaching learning based optimization approach for combined heat and power dispatch", Int J Elec Power and Energ Sys., 57, pp. 392-403 (2014).

23. Nguyen, T.T., Vo, D.N., and Ruong, A.V. "Cuckoo search algorithm for short-term hydrothermal scheduling", Appl Energy, 132, pp. 276-287 (2014).

24. Zhou, J., Liao, X., Ouyang, S., et al. "Multi-objective artificial bee colony algorithm for short-term scheduling of hydrothermal system", Electr Power Energy Syst., 55, pp. 542-553 (2014).

25. Das, S. and Bhattacharya, A. "Symbiotic organisms search algorithm for short-term hydrothermal scheduling”, Ain Shams Engg J., 9(4), pp. 499-516 (2016).

26. Roy, S., Rani, S., Bhattacharjee, K., et al. "Chemical reaction based optimization implemented to solve short-term hydrothermal generation scheduling problems", 3rd International Conference on Electrical Energy Systems (ICEES 2016), SSN college of Engineering, Tamilnadu, India, pp. 79-84 (2016).
27. Sutradhar, S., Dev, Choudhury, N.B., and Sinha, N. "Grey wolf optimizer for short-term hydrothermal scheduling problems", Michael Faraday IET International Sumit, 2015, Kolkata, India (2015).

28. Bhattacharjee, K., Bhattacharya, A., and nee Dey, S.H. "Real coded chemical reaction based optimization for short-term hydrothermal scheduling", Appl. Soft Comput., 24, pp. 962-976 (2014).

29. Roy, P.K., Pradhan, M., and Paul, T. "Krill herd algorithm applied to short-term hydrothermal scheduling problem", Ain Shams Engg. Jr., 9, pp. 31-43 (2018).

30. Swain, R.K., Barisal, A.K., Hota, P.K., et al. "Shortterm hydrothermal scheduling using clonal selection algorithm", Int. J. Elec. Power \& Energ. Sys., 33(3), pp. 647-656 (2011).

31. Balachander, T., Jeyanthy, P.A., and Devaraj, D. "Short term hydrothermal scheduling using flower pollination algorithm", 2017 IEEE International Conference on Intelligent Techniques in Control, Optimization and Signal Processing (INCOS), Srivilliputhur, India (2017).

32. Das, S., Bhattacharya, A., and Das, S. "Solution of short-term hydrothermal scheduling using sine cosine algorithm", Soft Comput., 22(19), pp. 6409-6427 (2018).

33. Dubey, H.M., Pandit, M., and Panigrahi, B.K. "Ant lion optimization for short-term wind integrated hydrothermal power generation scheduling", Int. J. Elec. Power \& Energ. Sys., 83, pp. 158-174 (2016).

34. Das, S., Bhattacharya, A., Chakraborty, A.K., et al. "Fixed head short-term hydrothermal scheduling using whale optimization algorithm considering the uncertainty of solar power", 2017 Ninth International Conference on Advanced Computing (ICoAC), Chennai, India (2017).

35. Nguyen, T.T. and Vo, D.N. "Modified cuckoo search algorithm for short-term hydrothermal scheduling", Electr Power Energy Syst, 65, pp. 271-281 (2015).

36. Das, S., Bhattacharya, A., and Chakraborty, A.K. "Solution of short-term hydrothermal scheduling problem using quasi-reflected symbiotic organisms search algorithm considering multi-fuel cost characteristics of thermal generator", Arab J Sci and Engg., 43, pp. 2931-2960 (2018).

37. Das, S., Bhattacharya, A., and Chakraborty, A.K. "Quasi-reflected ions motion optimization algorithm for short term hydrothermal scheduling", Neural Comput \& Applic, 29, pp. 123-149 (2018).

38. Narang, N. "Short-term hydrothermal generation scheduling using improved predator influenced civilized swarm optimization technique", Appl Soft Comput, 58, pp. 207-224 (2017).

39. Fang, N., Zhou, J., Zhang, R., et al. "A hybrid of real coded genetic algorithm and artificial fish swarm algorithm for short-term optimal hydrothermal scheduling”, Int J Elec Power and Energ Sys., 62, pp. 617-629 (2014). 
40. Bhattacharjee, K., Bhattacharya, A., and nee Dey, S.H. "Oppositional real coded chemical reaction based optimization to solve short-term hydrothermal scheduling problems", Int J Elec Power and Energ Sys, 63, pp. 145-157 (2014).

41. Zhang, J., Lin, S., and Qin, W. "A modified chaotic differential evolution algorithm for short-term optimal hydrothermal scheduling", Int J Elec Power and Energ Sys., 65, pp. 159-168 (2015).

42. Rasoul, Z.A., and Mohammadi-Ivatloo, B. "Shortterm hydrothermal generation scheduling by a modified dynamic neighborhood learning based particle swarm optimization", Int J Elec Power and Energ Sys., 67, pp. 350-367 (2015).

43. Roy, P.K. "Hybrid chemical reaction optimization approach for combined economic emission short-term hydrothermal scheduling", Elec Power Comp and Sys., 42(15), pp. 1647-1660 (2014).

44. Nadakuditi, G., Sharma, V., and Naresh, R. "Application of non-dominated sorting gravitational search algorithm with disruption operator for stochastic shortterm hydrothermal scheduling", IET Gener. Transm. Distrib., 10(4), pp. 862-872 (2016).

45. Goutham, N.K., Sharma, V., and Naresh R. "Hybridized Gravitational search algorithm for short-term hydrothermal scheduling", IETE Jr of Res., 62(4), pp. 468-478 (2016).

46. Feng, Z.K., Niu, W.J., Zhou, Z., et al. "Scheduling of short-term hydrothermal energy system by parallel multi-objective differential evolution", Appl Soft Comput, 61, pp. 58-71 (2017).

47. Zhang, J., Tang, Q., Chen, Y., et al. "A hybrid particle swarm optimization with small population size to solve the optimal short-term hydro-thermal unit commitment problem", Energy, 109, pp. 765-780 (2016).

48. Basu, M. "Quasi-oppositional group search optimization for hydrothermal power system", Int $J$ of Elec Power and Energ Sys., 81, pp. 324-335 (2016).

49. Feng, Z.-K.m, Niu, W.-J., Zhou, J.-Z., et al. "Parallel multi-objective genetic algorithm for short-term economic environmental hydrothermal scheduling", Energies, 10, pp. 1-22 (2017).

50. Heris, M.N., Babaei, A.F., Ivatloo, B.M., et al. "Improved harmony search algorithm for the solution of non-linear non-convex short-term hydrothermal scheduling", Energy, 151, pp. 226-237 (2018).
51. Nguyen, T.T., Vo, D.N., and Dinh, B.H. "An effectively adaptive selective cuckoo search algorithm for solving three complicated short-term hydrothermal scheduling problems", Energy, 155, pp. 930-956 (2018).

52. Wu, Y., Wu, Y., and Liu, X. "Couple-based particle swarm optimization for short-term hydrothermal scheduling", Appl., Soft Comput., 74, pp. 440-450 (2019).

53. Y., H.K., Liu, L., Su, L., et al. "Short-term hydropower generation scheduling using an improved cloud adaptive quantum-inspired binary social spider optimization algorithm", Water Resources Management, 33(7), pp. 2357-2379 (2019).

54. Gosh, S., Kaur, M., Bhullar, S., et al. "Hybrid ABCBAT for solving short-term hydrothermal scheduling problems", Energies, 12, pp. 1-15 (2019).

55. Saremi, S., Mirjalili, S., and Lewsis, A. "Grasshopper optimization algorithm: Theory and application", Advan in Engg Soft, 105, pp. 30-47 (2017).

56. Ge, X.L., Zhang, Li-Zi, Shu, J., et al. "Short-term hydropower optimal scheduling considering the optimization of water time delay", Elect Power Syst Res., 110, pp. 188-197 (2014).

57. Thakur, S., Chanwit, B., and Weerakon, O. "Optimal hydrothermal generation scheduling using selforganizing hierarchical PSO", IEEE PES General Meeting, pp. 1-6 (2010).

58. Roy, P.K., Sur, A., and Pradhan, D.K. "Optimal short-term hydro-thermal scheduling using quasioppositional teaching learning based optimization", Engineering Applications of Artificial Intelligence, 26, pp. 2516-2524 (2013).

59. Derac, J., Garcia, S., Molina, D., et al. "A practical tutorial on the use of nonparametric statistical tests as a methodology for comparing evolutionary and swarm intelligence algorithms", Swarm and Evolutionary Computation, 1, pp. 3-18 (2011).

60. Shenkin, D.J., Hand Book of Parametric and no Parametric Statistical Procedures, 4th Ed., Chapman \& Hall/CRC (2006).

\section{Appendix}

Input data are shown in Tables A.1 to A.4.

Table A.1. Volume limits of reservoir.

\begin{tabular}{ccccccc}
\hline Station & $\begin{array}{c}\text { Capacity } \\
(\mathbf{M W})\end{array}$ & $\begin{array}{c}\boldsymbol{V} \boldsymbol{O}_{h}^{\max } \\
\left(\mathbf{1 0}^{\mathbf{6}} \mathbf{m}^{\mathbf{3}}\right)\end{array}$ & $\begin{array}{c}\boldsymbol{V} \boldsymbol{O}_{h}^{\min } \\
\left.\mathbf{( 1 0}^{\mathbf{6}} \mathbf{m}^{\mathbf{3}}\right)\end{array}$ & $\begin{array}{c}\boldsymbol{V} \boldsymbol{O}_{h}^{\text {begin }} \\
\left(\mathbf{1 0}^{\mathbf{6}} \mathbf{m}^{\mathbf{3}}\right)\end{array}$ & $\begin{array}{c}\boldsymbol{V} \boldsymbol{O}_{h}^{\text {end }} \\
\left(\mathbf{1 0}^{\mathbf{6}} \mathbf{m}^{\mathbf{3}}\right)\end{array}$ & $\begin{array}{c}\boldsymbol{D} \boldsymbol{I}_{h}^{\max } \\
\left.\mathbf{( 1 0}^{\mathbf{4}} \mathbf{m}^{\mathbf{3}}\right)\end{array}$ \\
\hline 1 & 63.2 & 566 & 220 & 230 & 228 & 7.2 \\
2 & 80 & 1475.65 & 350 & 400 & 400 & 127.4 \\
3 & 4 & 394 & 150 & 160 & 159.9 & 5.76 \\
\hline
\end{tabular}


Table A.2. Fuel cost coefficients.

\begin{tabular}{cccccc}
\hline Unit no. & $\boldsymbol{A}$ & $\boldsymbol{B}$ & $\boldsymbol{C}$ & $\boldsymbol{E}$ & $\boldsymbol{F}$ \\
\hline 1 & 0.005 & 1.89 & 150 & 300 & 0.035 \\
2 & 0.0055 & 2 & 115 & 200 & 0.042 \\
3 & 0.006 & 3.5 & 40 & 200 & 0.042 \\
4 & 0.005 & 3.15 & 122 & 150 & 0.063 \\
5 & 0.005 & 3.05 & 125 & 150 & 0.063 \\
6 & 0.007 & 2.75 & 120 & 150 & 0.063 \\
7 & 0.007 & 3.45 & 70 & 200 & 0.053 \\
8 & 0.07 & 3.45 & 70 & 150 & 0.063 \\
\hline
\end{tabular}

Table A.3. Maximum and minimum generation limits of thermal units.

\begin{tabular}{ccc}
\hline Unit no & $\boldsymbol{T H}_{\boldsymbol{p}}^{\max }(\mathbf{M W})$ & $\boldsymbol{T} \boldsymbol{H}_{\boldsymbol{p}}^{\text {min }}(\mathbf{M W})$ \\
\hline 1 & 2340 & 234 \\
2 & 630 & 63 \\
3 & 500 & 50 \\
4 & 760 & 76 \\
5 & 1000 & 100 \\
6 & 210 & 21 \\
7 & 1000 & 100 \\
8 & 1200 & 120 \\
\hline
\end{tabular}

Table A.4. 24-hour load demand.

\begin{tabular}{cccc}
\hline Hour & $\begin{array}{c}\text { Load demand } \\
\text { (Test system I) }\end{array}$ & $\begin{array}{c}\text { Load demand } \\
\text { (Test system II) }\end{array}$ & $\begin{array}{c}\text { Load demand } \\
\text { (Test system III) }\end{array}$ \\
\hline 1 & 1050 & 1050 & 1050 \\
2 & 1600 & 1600 & 1600 \\
3 & 2500 & 2500 & 2500 \\
4 & 1700 & 1700 & 1700 \\
5 & 1550 & 1550 & 1550 \\
6 & 3450 & 3450 & 3450 \\
7 & 2500 & 5500 & 3500 \\
8 & 2300 & 2300 & 2300 \\
9 & 2000 & 7000 & 4000 \\
10 & 2550 & 6550 & 3550 \\
11 & 2500 & 5500 & 3500 \\
12 & 2200 & 5200 & 4200 \\
13 & 2000 & 4800 & 4000 \\
14 & 2100 & 4600 & 4100 \\
15 & 2200 & 4200 & 4200 \\
16 & 2150 & 4150 & 4150 \\
17 & 2020 & 4020 & 4020 \\
18 & 2480 & 3880 & 3880 \\
19 & 2550 & 3650 & 3650 \\
20 & 2400 & 3400 & 3400 \\
21 & 2450 & 3450 & 3450 \\
22 & 2140 & 3140 & 3140 \\
23 & 2500 & 2950 & 2950 \\
24 & 2550 & 2850 & 2850 \\
\hline
\end{tabular}




\section{Biographies}

Diptanu Das received his BE in Electrical Engineering from NIT Agartala, India (formerly Tripura Engineering College) in 2009 and his MTech in Electrical Engineering from NIT Agartala, India in 2011. He is currently pursuing a $\mathrm{PhD}$ degree at the Department of Electrical Engineering at NIT Agartala, India. He is also working as an Assistant Professor at the Department of Electrical Engineering of NIT Agartala, India. His areas of interest include power system optimization, power electronics, power, and energy system.

Aniruddha Bhattacharya received his BSc Engineering in Electrical Engineering from Regional Institute of Technology, Jamshedpur, India in 2000, MEE and PhD in Electrical Power System from Jadavpur University, Kolkata, India in 2008 and 2011, respectively. His employment experience includes Siemens Metering Limited, India; Jindal Steel and Power Limited, Raigarh, India; Bankura Unnyani Institute of
Engineering, Bankura, India; Dr. B. C. Roy Engineering College, Durgapur, India; National Institute of Technology Agartala. He is currently an Assistant Professor at the Electrical Engineering Department, NIT Durgapur, India. His areas of interest include power system load flow, optimal power flow, economic load dispatch, and soft computing applications to power system problems.

Rup Narayan Ray received his BE in Electrical Engineering from University of Calcutta, India in 1985, and his ME from Bengal Engineering College, Shibpur, India with specialization in Electrical Machines in 1995 and $\mathrm{PhD}$ in Electrical Engineering from Jadavpur University, Kolkata, India in 2010. He joined teaching as a Lecturer at NIT Agartala (formerly Tripura Engineering College) in 1987. He is currently an Associate Professor at the Electrical Engineering Department, NIT Agartala, India. His areas of interest include electrical machines and drives, power qualities, and distributed generations. 